Review

\title{
Physical Activity and Nutrition INfluences in Ageing: Current Findings from the PANINI Project
}

Anna C. Whittaker 1,2,*, Evans A. Asamane ${ }^{1}$, Justin A. Aunger ${ }^{1}$, Dmitriy Bondarev ${ }^{3}$, Andrea Cabbia ${ }^{4}$, Paul D. Doody ${ }^{1}$, Noémie Gensous ${ }^{5}$, Barbara Iadarola ${ }^{6,7}$, Keenan A. Ramsey ${ }^{8}$, Belina Rodrigues ${ }^{9,10,11}$, Muhammad Rizwan Tahir ${ }^{12}$, Suey S.Y. Yeung ${ }^{8}$, on behalf of the PANINI Consortium $\dagger$

1 School of Sport, Exercise and Rehabilitation Sciences, University of Birmingham, Birmingham B15 2TT, UK

2 Faculty of Health Sciences and Sport, University of Stirling, Stirling FK9 4LA, Scotland, UK

3 Gerontology Research Center \& Faculty of Sport and Health Sciences, University of Jyväskylä, Jyväskylä 40014, Finland

4 Department of Biomedical Engineering, Eindhoven University of Technology, Groene Loper, Eindhoven 5612 AP The Netherlands

5 Department of Experimental, Diagnostic, and Specialty Medicine (DIMES), University of Bologna, Bologna 40126, Italy

6 Personal Genomics, University of Verona, Via Roveggia 43B, Verona 37136, Italy

7 Department of Biotechnology, University of Verona, Strada Le Grazie 15, Verona 37134, Italy

8 Department of Human Movement Sciences, Faculty of Behavioural and Movement Sciences, Vrije Universiteit Amsterdam, Amsterdam Movement Sciences, Amsterdam 1081 BT, The Netherlands

9 Life and Health Sciences Research Institute (ICVS), School of Medicine, University of Minho, Braga 4710, Portugal

10 ICVS/3B's, PT Government Associate Laboratory, Braga/Guimarães 4710, Portugal

11 Clinical Academic Center-Braga (2CA-B), Braga 4710, Portugal

12 Department of Microbiology and System Biology, The Netherlands Organisation for Applied Scientific Research, Zeist $3704 \mathrm{HE}$, The Netherlands

$\dagger$ On behalf of the PANINI Consortium: Anna C. Whittaker, School of Sport, Exercise \& Rehabilitation Sciences, University of Birmingham, UK; Evans A.

\section{f Open Access}

Received: 19 April 2019 Accepted: 13 June 2019 Published: 02 July 2019

Copyright @ 2019 by the author(s). Licensee Hapres, London, United Kingdom. This is an open access article distributed under the terms and conditions of Creative Commons Attribution $\underline{4.0 \text { International License. }}$ Asamane, School of Sport, Exercise \& Rehabilitation Sciences, University of Birmingham, UK; Justin Aunger, School of Sport, Exercise \& Rehabilitation Sciences, University of Birmingham, UK; Maria Giulia Bacalini, Institute of Neurological Sciences (IRCCS), Bologna, Italy; Dmitriy Bondarev, Gerontology Research Center \& Faculty of Sport and Health Sciences, University of Jyväskylä, Finland; Bart Bongers, Department of Epidemiology, Faculty of Health, Medicine and Life Sciences, Maastricht University, The Netherlands; Andrea Cabbia, Department of Biomedical Engineering, Eindhoven University of Technology, Netherlands; Massimo Delledonne, Personal Genomics, University of Verona, Italy; Paul Doody, School of Sport, Exercise \& Rehabilitation Sciences, University of Birmingham, UK; Taija Finni, Neuromuscular Research Center, Faculty of Sport and Health Sciences, University of Jyväskylä, Finland; Claudio Franceschi, 
Department of Experimental, Diagnostic, and Specialty Medicine (DIMES), University of Bologna, Bologna, Italy; Paolo Garagnani, Department of Experimental, Diagnostic, and Specialty Medicine (DIMES), University of Bologna, Bologna, Italy; Noémie Gensous, Department of Experimental, Diagnostic, and Specialty Medicine (DIMES), University of Bologna, Bologna, Italy; Carolyn Greig, School of Sport, Exercise \& Rehabilitation Sciences, MRCArthritis Research UK Centre for Musculoskeletal Ageing Research, University of Birmingham, UK \& NIHR Birmingham Biomedical Research Centre, University Hospitals Birmingham NHS Foundation Trust and University of Birmingham, UK; Peter Hilbers, Department of Biomedical Engineering, Eindhoven University of Technology, The Netherlands; Barbara Iadarola, Personal Genomics, University of Verona, Italy; Victor Kallen, The Netherlands Organisation for Applied Scientific Research, The Netherlands; Katja Kokko, Gerontology Research Center \& Faculty of Sport and Health Sciences, University of Jyväskylä, Finland; Anna Elisa Laria, Personal Genomics, University of Verona, Italy; Janet Lord, Institute of Inflammation and Ageing, Medical School \& MRC- Arthritis Research UK Centre for Musculoskeletal Ageing Research, University of Birmingham, UK; Andrea B. Maier, Department of Human Movement Sciences, Amsterdam Movement Sciences, VU University Amsterdam, The Netherlands \& Department of Medicine and Aged Care, Royal Melbourne Hospital, University of Melbourne, Melbourne, Australia; Carel G.M. Meskers, Department of Rehabilitation Medicine, VU University Medical Center \& Amsterdam Movement Sciences, Amsterdam, The Netherlands; Keenan Ramsey, Department of Human Movement Sciences, Amsterdam Movement Sciences, VU University Amsterdam, The Netherlands; Esmee M. Reijnierse, Department of Medicine and Aged Care, Royal Melbourne Hospital, University of Melbourne, Melbourne, Australia; Belina Rodrigues, School of Medicine, University of Minho, Portugal; Nadine Correia Santos, Life and Health Sciences Research Institute (ICVS), School of Medicine, University of Minho, and ICVS/3B's -PT Government Associate Laboratory, Braga/Guimarães, Portugal; Nuno Sousa, Life and Health Sciences Research Institute (ICVS), School of Medicine, University of Minho, and ICVS/3B's-PT Government Associate Laboratory, Braga/Guimarães, Portugal; Sarianna Sipila, Gerontology Research Center \& Faculty of Sport and Health Sciences, University of Jyväskylä, Finland; Muhammad Rizwan Tahir, Department of Microbiology and System Biology, The Netherlands Organisation for Applied Scientific Research, Zeist, The Netherlands; Marijke C Trappenburg, Department of Internal Medicine, VU University Medical Center \& Amstelland Hospital, The Netherlands; Janice L. Thompson, School of Sport, Exercise \& Rehabilitation Sciences, University of Birmingham, UK; Nico van Meeteren, Health Holland, The Hague, \& Faculty of Health, Medicine and Life Sciences, Maastricht University, The Netherlands; Natal van Riel, Department of Biomedical Engineering, Eindhoven University of Technology, The Netherlands; Suey Yeung, Department of Human Movement Sciences, Amsterdam Movement Sciences, VU University Amsterdam, The Netherlands. 
* Correspondence: Anna C. Whittaker, Email: a.c.whittaker@bham.ac.uk.

\section{ABSTRACT}

Background: The ageing of the population is a global challenge and the period of life spent in good health, although increasing, is not keeping pace with lifespan. Consequently, understanding the important factors that contribute to healthy ageing and validating interventions and influencing policy to promote healthy ageing are vital research priorities.

Method: The PANINI project is a collaboration of 20 partners across Europe examining the influence of physical activity and nutrition in ageing. Methods utilised encompass the biological to the social, from genetics to the influence of social context. For example, epigenetic, immunological, and psychological assessments, and nutritional and sports science-based interventions have been used among older adults, as well as mathematical modelling and epidemiology. The projects are multi-disciplinary and examine health outcomes in ageing from a range of perspectives.

Results: The results discussed here are those emerging thus far in PANINI from 11 distinct programmes of research within PANINI as well as projects crosscutting the network. New approaches, and the latest results are discussed.

Conclusions: The PANINI project has been addressing the impact of physical activity and nutrition on healthy ageing from diverse but interlinked perspectives. It emphasises the importance of using standardized measures and the advantages of combining data to compare biomarkers and interventions across different settings and typologies of older adults. As the projects conclude, the current results and final data will form part of a shared dataset, which will be made open access for other researchers into ageing processes.

KEYWORDS: ageing; epigenetics; frailty; genetics; inflammation; nutrition; physical activity; physical function; well-being

\section{INTRODUCTION}

The ageing of the population is a global challenge: current data suggests that by the year 2020 about one fifth of the population of Europe will be aged 65+ years and there will be a tripling of the number of individuals aged $85+$ years by 2050 [1]. Although life expectancy is increasing by 2 years per decade on average, the period of life spent in good health (health span) although also longer, is not keeping pace with lifespan to the same extent. This means that most Europeans spend their latter years in poor health. Thus, understanding the important factors that contribute to healthy ageing versus frailty and validating interventions and influencing policy to promote healthy ageing is a cross-cutting research priority in Europe. Healthy ageing is life spent in relatively good health with independence and good quality of life across physical and mental domains 
versus living with limited independence and poor quality of life. This review will describe briefly the Physical Activity and Nutrition INfluences In ageing (PANINI) project, the different work packages within the project which address the global challenge of healthy ageing, and the recent findings and ongoing research. Finally, future directions informed by this research will be discussed.

The PANINI project is filling a key knowledge gap by considering the impact of lifestyle factors on healthy ageing and disease, specifically physical activity and nutrition. These factors and their influence on various bodily systems and the net effect on the individual should not be considered in isolation. Consequently, the PANINI project is an innovative multi-disciplinary training and research network examining the influence of physical activity and nutrition on age-related changes from gene to societal level [2-4] As a result, PANINI is very diverse in the nature of research conducted. However, it devised of a toolkit of multi-factorial important measures of function and wellbeing in ageing using existing gold standards and/or previously validated and commonly used measures across existing datasets. This means that each project, as far as was possible, has integrated the measurement of a standard set or part of a standard set of measures for comparison across populations in addition to answering their own specific research questions. The PANINI project consists of three main research work-packages: Standardisation of measures; Physical Activity; and Nutrition. The present review is an update and summary of PANINI network findings and implications thus far. Table 1 summarises the completed and ongoing individual projects within each work package and associated references, and papers in preparation.

Table 1. Summary of PANINI completed and ongoing activities and associated references.

\begin{tabular}{|c|c|c|}
\hline Work Package & Project/Activity & $\begin{array}{l}\text { Associated } \\
\text { References }\end{array}$ \\
\hline 1. Standardisation & $\begin{array}{l}\text { - } \quad \text { The physical activity and nutritional influences in ageing toolkit: } \\
\text { methodology } \\
\text { - } \quad \text { Malnutrition is associated with dynamic physical performance. } \\
\text { nutrition and physical activity guidelines and physical function and } \\
\text { activity in older adults } \\
\text { - } \quad \text { Systematic review of objectively measured sedentary behavior and } \\
\text { - } \quad \text { Systematic review of objectively measured sedentary behavior and } \\
\text { - } \quad \text { Are different geriatric domains different constructs with respect to } \\
\text { - } \quad \text { muscle measures (muscle mass, muscle function, and muscle strength)? } \\
\text { - A machine learning approach to investigate the relation between physical } \\
\text { activity, nutrition and the pace of ageing in the PANINI shared dataset. }\end{array}$ & $\begin{array}{l}\text { ongoing } \\
\text { ongoing } \\
\text { ongoing } \\
\text { ongoing } \\
\text { ongoing }\end{array}$ \\
\hline
\end{tabular}


Table 1. Cont.

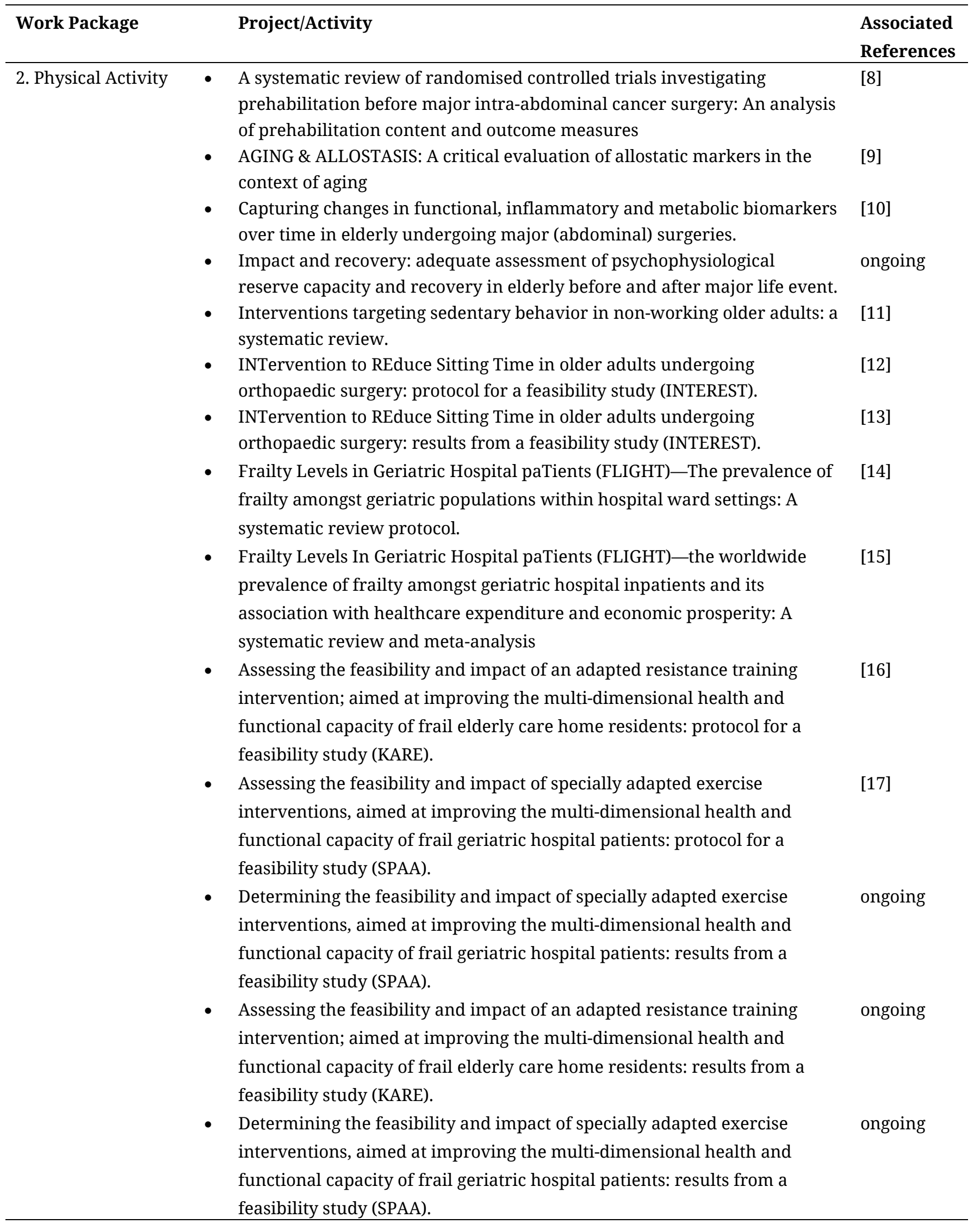


Table 1. Cont.

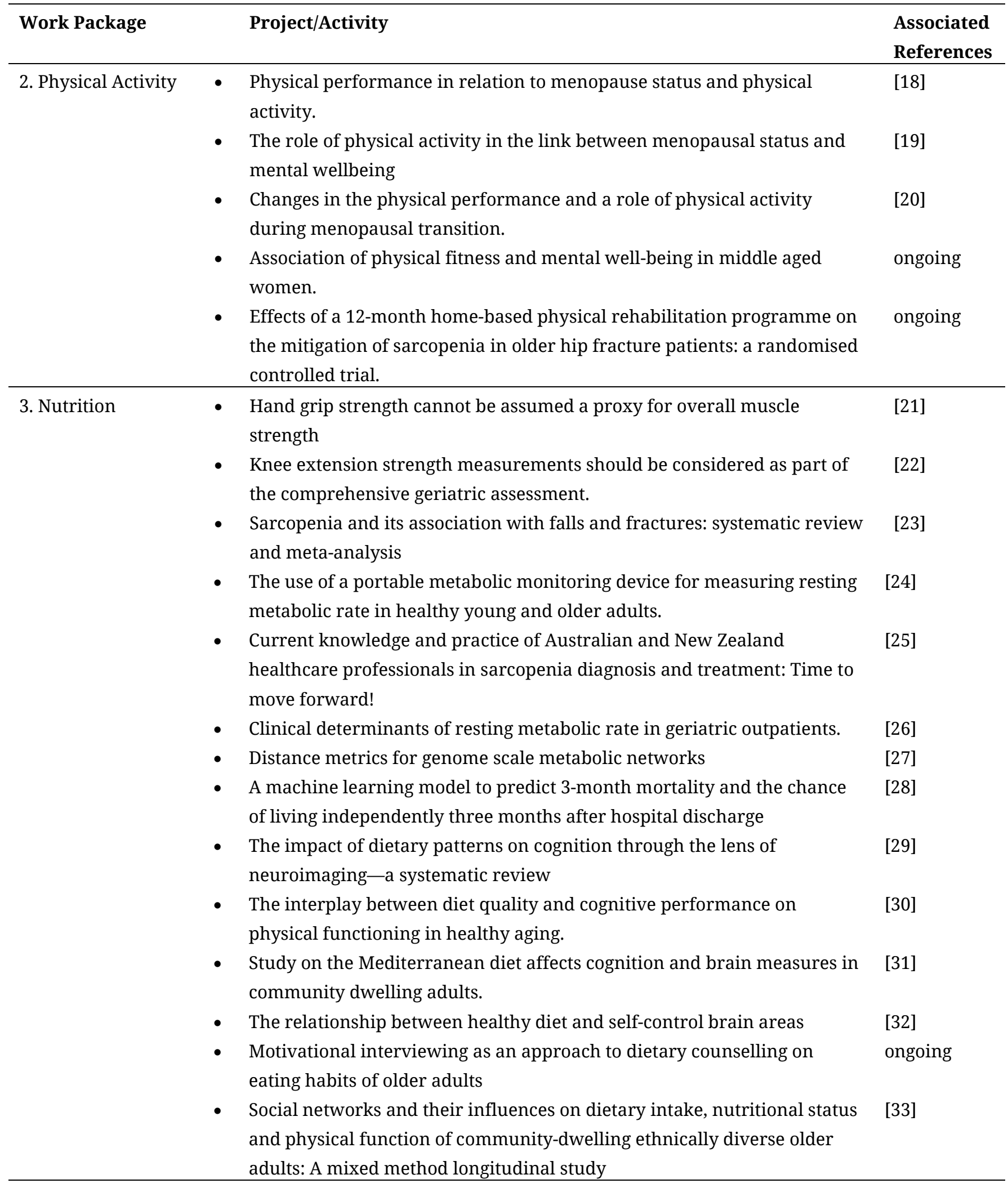


Table 1. Cont.

\begin{tabular}{|c|c|c|}
\hline Work Package & Project/Activity & $\begin{array}{l}\text { Associated } \\
\text { References }\end{array}$ \\
\hline \multirow[t]{6}{*}{ 3. Nutrition } & $\begin{array}{l}\text { The association between nutritional status, cognition and physical } \\
\text { function of community-dwelling ethnically diverse older adults: A } \\
\text { longitudinal study. } \\
\text { - Perceptions and factors influencing eating behaviours and physical } \\
\text { function in community-dwelling ethnically diverse older adults: a } \\
\text { longitudinal qualitative study }\end{array}$ & [34] \\
\hline & $\begin{array}{l}\text { - The interplay of dietary fibre and social networks on cognition among } \\
\text { community-dwelling older adults: A moderation model }\end{array}$ & [36] \\
\hline & $\begin{array}{l}\text { One-year Mediterranean-diet promotes epigenetic rejuvenation in the } \\
\text { elderly participants of the NU-AGE study: country and sex-specific } \\
\text { effects. }\end{array}$ & [37] \\
\hline & - DNA methylation and skeletal muscle aging in humans & [38] \\
\hline & $\begin{array}{l}\text { - Development of gene-targeted epigenetic aging clock using the Agena } \\
\text { Bioscience EpiTYPER system }\end{array}$ & ongoing \\
\hline & $\begin{array}{l}\text { Enhanced targeted resequencing by optimized combination of } \\
\text { enrichment technology and DNA insert length }\end{array}$ & [39] \\
\hline \multirow[t]{3}{*}{ 4. Dissemination } & - Consortium mission statement & [2] \\
\hline & - Lengthening healthy life & [3] \\
\hline & - The need for ageing research in Europe & [4] \\
\hline
\end{tabular}

All studies conformed to the Declaration of Helsinki and regulations established within the respective governmental and research organisations' regulations. All studies involving human participants gained ethical approval and written informed consent; ethical approvals for each individual study were also submitted to the funder and are available on request.

\section{WORK PACKAGE 1: STANDARDISING TOOLS AND DATA}

Within this work package, it was aimed to understand the interaction between the domains of nutrition status and physical status in older adults as a matter of clinical urgency. Using large datasets and combined data across the PANINI consortium it was aimed to gain a better understanding of these domains and especially their interaction. Heterogeneity in the methods used to assess nutrition and physical domains across different studies presents a challenge [40]; thus standardisation of methods is required. The PANINI Toolkit was devised by the consortium and is made up of best practice measures in five domains (background, anthropometrics, nutrition, physical status, and psychological and cognitive health) for assessing nutritional and physical status across five domains [5]. Measures exist within datasets previously collected by PANINI partners and have been applied across new PANINI projects. The measures comprising the PANINI toolkit are summarised in Table 2. Application of the PANINI toolkit across new PANINI projects and 
standardisation of data entry allows for comparability between different ageing populations and interventions by using the same protocol baseline and outcome measurements (the PANINI Protocol and Case Report Form, to be made available on the PANINI website in June 2019: https://www.birmingham.ac.uk/generic/panini/index.aspx). This standardization of measures has allowed us to study the interaction between the nutrition and physical activity and effects on physical and mental function across different ageing profiles and to compare effectiveness of interventions conducted with healthcare and non-academic partner settings. The eventual combined PANINI dataset will be made open access via the University of Birmingham data repository within 12 months of the end of the project and will be accessible by request using a data access form through the PANINI website, which will be reviewed by the PANINI steering committee. PANINI is using these data to develop a set of physical activity recommendations for older adults across the range of frailty and dependency levels which will be integrated with the knowledge gained regarding nutritional intake and energy balance across the network. This will be integrated into a set of policy-ready recommendations for healthy ageing, as one of the deliverables of PANINI (Table 3).

Table 2. Summary of measures of the PANINI Toolkit by domain.

\begin{tabular}{|c|c|c|c|}
\hline Domain & Sub-Domains & Tool & Measure \\
\hline \multirow[t]{2}{*}{$\begin{array}{l}\text { 1. Socio- } \\
\text { demographics }\end{array}$} & $\begin{array}{l}\text { Socio- } \\
\text { demographic }\end{array}$ & PANINI Questionnaire & $\begin{array}{l}\text { Nationality, language, education, and } \\
\text { occupation }\end{array}$ \\
\hline & Social & PANINI Questionnaire & $\begin{array}{l}\text { Marital status, living situation, and } \\
\text { social circumstances }\end{array}$ \\
\hline \multirow{7}{*}{$\begin{array}{l}\text { 2. General } \\
\text { Health }\end{array}$} & Intoxicants & PANINI Questionnaire & Alcohol, smoking, and drug use \\
\hline & Medical history & PANINI Questionnaire & Past and current medical conditions \\
\hline & Medication use & PANINI Questionnaire & Current medication use \\
\hline & \multirow[t]{2}{*}{ Anthropometrics } & $\begin{array}{l}\text { Calibrated height and } \\
\text { measuring system }\end{array}$ & Height $(\mathrm{cm})$ and weight $(\mathrm{kg})$ \\
\hline & & Tape measure & $\begin{array}{l}\text { Waist, hip, calf, and mid-arm } \\
\text { circumferences }(\mathrm{cm})\end{array}$ \\
\hline & \multirow[t]{2}{*}{ Body Composition } & $\begin{array}{l}\text { Dual-energy X-ray } \\
\text { absorptiometry (DXA) }\end{array}$ & $\begin{array}{l}\text { Fat mass, lean soft-tissue mass } \\
\text { (comprising muscle, inner organs, and } \\
\text { body water), and bone mineral } \\
\text { content (kg) }\end{array}$ \\
\hline & & $\begin{array}{l}\text { Bioelectrical Impedance } \\
\text { Analysis (BIA) }\end{array}$ & $\begin{array}{l}\text { Fat mass, lean soft-tissue mass } \\
\text { (comprising muscle, inner organs, and } \\
\text { body water), and bone mineral } \\
\text { content (kg) }\end{array}$ \\
\hline
\end{tabular}


Table 2. Cont.

\begin{tabular}{|c|c|c|c|}
\hline Domain & Sub-Domains & Tool & Measure \\
\hline \multirow[t]{3}{*}{ 3. Nutrition } & Malnutrition & $\begin{array}{l}\text { Mini Nutritional } \\
\text { Assessment (MNA) }\end{array}$ & $\begin{array}{l}\text { Nutritional status (points) (normal } \\
\text { nutritional status, at risk of malnutrition, } \\
\text { malnourished) }\end{array}$ \\
\hline & Water consumption & PANINI Questionnaire & $\begin{array}{l}\text { Daily amount of water consumption } \\
\text { (mL/day) }\end{array}$ \\
\hline & Nutritional intake & $\begin{array}{l}\text { Food frequency } \\
\text { questionnaire }\end{array}$ & Macronutrient and micronutrient intake \\
\hline \multirow{11}{*}{$\begin{array}{l}\text { 4. Physical } \\
\text { Activity \& } \\
\text { Physical } \\
\text { Performance }\end{array}$} & \multirow[t]{3}{*}{ Physical Activity } & $\begin{array}{l}\text { Modified Minnesota } \\
\text { Leisure Time Activities } \\
\text { (MLTA) Questionnaire }\end{array}$ & Self-reported physical activity (kcal/week) \\
\hline & & $\begin{array}{l}\text { International Physical } \\
\text { Activity Questionnaire } \\
\text { Short Form (IPAQ-s) } \\
\end{array}$ & $\begin{array}{l}\text { Self-reported physical activity (vigorous } \\
\text { activity, moderate activity, walking, sitting) } \\
\text { (h/day) }\end{array}$ \\
\hline & & Accelerometer s & $\begin{array}{l}\text { Physical activity, energy expenditure, and } \\
\text { sedentary behaviour }\end{array}$ \\
\hline & Mobility & PANINI Questionnaire & Self-reported mobility \\
\hline & \multirow[t]{6}{*}{$\begin{array}{l}\text { Physical } \\
\text { performance }\end{array}$} & $\begin{array}{l}\text { Short Physical } \\
\text { Performance Battery }\end{array}$ & $\begin{array}{l}\text { Composite physical performance score } \\
\text { (points) }\end{array}$ \\
\hline & & Four meter $(4 \mathrm{~m})$ walk test & Gait speed (m/s) \\
\hline & & Chair stand test & Time to complete 5 stands from a chair (s) \\
\hline & & Balance tests & $\begin{array}{l}\text { Ability to maintain balance for } \\
10 \text { s in side by side, tandem, and semi- } \\
\text { tandem positions (yes/no, points) }\end{array}$ \\
\hline & & $\begin{array}{l}\text { Balance tests with eyes } \\
\text { closed }\end{array}$ & $\begin{array}{l}\text { Ability to maintain balance for } \\
10 \text { s in side by side, tandem, and semi- } \\
\text { tandem positions with eyes closed (yes/no, } \\
\text { points) }\end{array}$ \\
\hline & & Handheld dynamometer & Hand grip strength (kg) \\
\hline & Frailty & $\begin{array}{l}\text { Fried Frailty Phenotype } \\
\text { Criteria }\end{array}$ & Frailty status (robust, pre-frail or frail) * \\
\hline \multirow{4}{*}{$\begin{array}{l}\text { 4. Physical } \\
\text { Activity \& } \\
\text { Physical } \\
\text { Performance }\end{array}$} & \multirow[t]{4}{*}{ Frailty } & $\begin{array}{l}\text { Shrinking: Weight loss } \\
\text { questions } * *\end{array}$ & $\begin{array}{l}\text { Shrinking: Unintentional weight loss in } \\
\text { past year }{ }^{* *} \text { (yes/no) }\end{array}$ \\
\hline & & $\begin{array}{l}\text { Weakness: Handheld } \\
\text { dynamometer }\end{array}$ & Weakness: Hand grip strength (kg) \\
\hline & & $\begin{array}{l}\text { Poor endurance: } \\
\text { Depression Center for } \\
\text { Epidemiologic Studies } \\
\text { Depression Scale (CES-D) } \\
* * *\end{array}$ & Poor endurance: Depression score (points) \\
\hline & & Slowness: $4 \mathrm{~m}$ walk test & Slowness: Gait speed (m/s) \\
\hline
\end{tabular}


Table 2. Cont.

\begin{tabular}{|c|c|c|c|}
\hline Domain & Sub-Domains & Tool & Measure \\
\hline \multirow{4}{*}{$\begin{array}{l}\text { 4. Physical } \\
\text { Activity \& } \\
\text { Physical } \\
\text { Performance }\end{array}$} & Frailty & $\begin{array}{l}\text { Low activity: MLTA } \\
\text { Questionnaire }\end{array}$ & Low Activity: Physical activity (kcal/week) \\
\hline & \multirow[t]{2}{*}{ Falls } & $\begin{array}{l}\text { Short Fall Efficacy Scale } \\
\text { International (FES-I) }\end{array}$ & Fear of falling (points) \\
\hline & & PANINI Questionnaire & Falls history information in past year \\
\hline & $\begin{array}{l}\text { Activities of daily } \\
\text { living }\end{array}$ & $\begin{array}{l}\text { Katz Index of } \\
\text { Independence in } \\
\text { Activities of Daily Living } \\
\text { (IADL) }\end{array}$ & $\begin{array}{l}\text { Ability to independently complete } \\
\text { activities of daily life (yes/no, points) }\end{array}$ \\
\hline \multirow[t]{2}{*}{$\begin{array}{l}\text { 5. Psychological } \\
\text { \& Cognitive } \\
\text { Health }\end{array}$} & Cognition & $\begin{array}{l}\text { Standardised Mini } \\
\text { Mental State } \\
\text { Examination (SMMSE) }\end{array}$ & Cognitive status (points) \\
\hline & Psychological & $\begin{array}{l}\text { Geriatric Depression } \\
\text { Scale-15 (GDS-15) }\end{array}$ & $\begin{array}{l}\text { Depression (normal, mild depression, } \\
\text { moderate depression, severe } \\
\text { depression) }\end{array}$ \\
\hline
\end{tabular}

Bulleted items represent individual measures within a composite measure. Measures from the PANINI Questionnaire are assessed through questions developed by the PANINI consortium. * All criteria of the Fried Frailty Phenotype are assessed as above or below a specified threshold cutoff (adjusted BMI, age, height, and/or sex as necessary. ** Unintentional weight loss is assessed by self-reported loss $\geqslant 4.5 \mathrm{~kg}$ in the year before the current evaluation or unintentional weight loss $\geqslant 5 \%$ of the previous year's body weight is used to assess the "shrinking" criteria of the Fried Frailty Phenotype. *** The evaluation of two statements (a) "I felt that everything I did was an effort” and (b) I could not get going from the CES-D scale are used to assess the "poor endurance” criteria of the Fried Frailty Phenotype.

Table 3. Summary of PANINI scientific deliverables/milestones (ESR = Early Stage Researcher).

\begin{tabular}{lll}
\hline Title & WP & Description \\
\hline ESR1 Toolkit & 1 & Standardised measures collated and toolkit developed \\
\hline ESR6 Study 1 & $2-3$ & $\begin{array}{l}\text { Data collection complete on 3-year follow-up of cohort on neurocognitive } \\
\text { parameters, dietary intake and physical function. }\end{array}$ \\
\hline ESR3 Study 1 & 2 & $\begin{array}{l}\text { Systematic review of sedentary time interventions and acute study } \\
\text { observational analysis complete }\end{array}$ \\
\hline ESR1 Verification & 1 & Check that standardised measures are implemented across all studies \\
\hline ESR2 Study 1 & 2 & Data collection completion and analysis of Study 1 \\
\hline ESR6 Sub-study & $2-3$ & $\begin{array}{l}\text { Dietary pattern profiles. Selection of clusters for nutrient analysis and } \\
\text { actigraphy. }\end{array}$ \\
\hline ESR6 Model & $2-3$ & Definition of bio-mathematical models that predict cognitive ageing. \\
\hline ESR9 Study 1 & 3 & Clinical phenotype of sarcopenia data collected and analysed \\
\hline ESR10 Study 1 & 3 & Genome wide analysis of NUAGE diet study complete \\
\hline ESR11 Lit search & 3 & Literature search of genetic determinants of ageing-related conditions \\
\hline ESR8 Study 1 & $2-3$ & Literature review complete, assessment battery operational \\
\hline ESR4 Study 1 & 3 & Completion and analysis of dietary assessment methods data \\
\hline ESR5 Study 1 & 2 & Computational model of skeletal muscle metabolism developed \\
\hline ESR6 Sub-sample & $2-3$ & Data collection complete on essential nutrients and cognition. \\
\hline
\end{tabular}


Table 3. Cont.

\begin{tabular}{lll}
\hline Title & WP & Description \\
\hline ESR8 Pilot study & $2-3$ & Pilot stage complete, standardized assessment battery complete \\
\hline ESR3 Study 2 & 2 & Feasibility trial for reducing sitting time pre-surgery complete \\
\hline ESR7 Dataset & 2 & Complete cross-sectional data collection \\
\hline ESR8 Study 1 & $2-3$ & Participants recruited and data analysed \\
\hline ESRs10 \&11 & 3 & $\begin{array}{l}\text { Completion of candidate gene \& DNA methylation analysis pre/post } \\
\text { intervention }\end{array}$ \\
\hline Enalysis & & Complete pre-surgical exercise intervention data collection \\
\hline ESR1 Collation & 1 & Data collation across all studies into shared database \\
\hline ESRs2,4 Study 2 & 3 & Completion of Study 2 \\
\hline ESR6 Analysis & $2-3$ & Complete longitudinal analysis (3- \& 6-year follow-up). \\
\hline ESRs 2,3,6,8,9 & $2-3$ & All samples from interventions to UNIBO for epigenetic analysis \\
\hline ESR7 Follow-up & 2 & Follow-up data in early and late perimenopausal women collected \\
\hline ESR8 Study 1 & $2-3$ & Data collection complete on main trial in patients \\
\hline ESR5 Study 2 & 2 & Model applied to active versus sedentary adult data \\
\hline ESRs 3-4 Study 3 & 2 & Data collection complete and analysed for third studies for ESRs 3-4 \\
\hline ESR8 Data analysis & $2-3$ & $\begin{array}{l}\text { Data analysis \& manuscripts complete on acute and post-op intervention } \\
\text { effects }\end{array}$ \\
\hline ESRs 2,3,6,8,9 & $2-3$ & UNIBO for epigenetic analysis complete \\
\hline
\end{tabular}

One of the initial set of analyses across multiple datasets within PANINI focused on malnutrition and physical function. Malnutrition and poor physical performance are both conditions that increase in prevalence with age [41], however, their clinically relevant interrelation has not been thoroughly studied. PANINI has studied the strength of the association between malnutrition and measures of both static and dynamic physical performance as a reflection of strength and power of muscle as a key linking substrate in a cohort of geriatric outpatients. It was found that malnutrition was associated with dynamic (chair stand test, gait speed, and timed up and go), rather than static (hand grip strength and balance) measures of physical performance [6]. Malnutrition was most strongly associated with chair stand test (the time required for an individual to stand up and down from a chair five times) and gait speed (the time it takes for an individual to walk 4 meters at normal pace). Less strong but significant associations were found between malnutrition and timed-upand-go test (the time it takes for an individual to stand up from a chair, walk three meters, turn around, walk back to the chair, and sit down) test. There was no significant association between malnutrition and hand grip strength (an individual's ability to apply maximum force to a handheld dynamometer) or balance (the ability to maintain balance in side-by-side, semi-tandem, and tandem stances for 10 seconds). The expertise on malnutrition as well as physical activity and physical function measures within the cohort also helped shape the content of the PANINI toolkit. This was then implemented into new data collection within PANINI, meaning projects were able to incorporate and analyse more multi-disciplinary 
measures and examine their associations through collaboration within the network.

A further part of the joint PANINI initiative on data collection, data sharing, and public engagement, was a public engagement event at the Vrije University Amsterdam called "PANINI: Recipe for Becoming Older". This event engaged a group of Dutch older adults, assessed their knowledge of Dutch nutrition and physical activity guidelines through questionnaires, and tested their functional status through a series of physical function and anthropometric measurements. It also provided education through a series of lectures pertaining to healthy ageing and engagement activities. Participants received feedback on their performance on the knowledge questionnaires as well as their vitality measurements. Data collected were used to study the relationship between knowledge of Dutch nutrition and physical activity guidelines and physical function (hand grip strength, gait speed, and physical activity min/week) and asked the question: Is knowing better doing better? It was found that in this inception cohort of generally healthy and motivated older adults, there was no association between knowledge of guidelines and physical function [7].

\section{WORK PACKAGE 2: PHYSICAL ACTIVITY}

The loss of skeletal muscle mass and function during the ageing process (sarcopenia), when associated with weight loss, poor physiological reserves, fatigue, weakness, slow walking speed, reduced balance and physical inactivity, results in frailty [42]. Low physical activity and higher sedentary behaviour among elders impacts on sarcopenia leading to frailty and mortality [43]. Thus, early detection and mitigation through sensitive biomarkers and targeted interventions is essential to ensure healthy ageing. The Physical Activity work package has incorporated studies of the impact of physical activity on muscle cell function through to acute effects of sedentary time on physical (muscle) and psychological (mental well-being and cognition) function.

Understanding the biology and physiology behind the development of frailty is an initial step required to develop appropriate interventions. PANINI is addressing this through focusing on muscle function, endocrine function, and inflammation in ageing at the cell and system level. These biological and physiological changes are being studied in a range of older populations of differing frailty and mobility and pre/post novel tailored interventions to reduce sedentary time, increase activity and improve physical function. Many of the measures incorporated in these studies are from the PANINI toolkit to allow comparability (see Table 2).

Physical activity interventions need to be appropriate for older adults of a range of health, frailty and independence levels thus must be tailored to the individual. For example, major surgery induces stress, which combined with the prevailing physically passive coping strategy can be harmful for patients, particularly when frail. PANINI is testing a novel 
intervention known as 'better in, better out' which promotes a prophysical activity and social environment to patients before and during the entire surgical trajectory to prevent poor recovery post-surgery [44].

Limited mobility and independence can hamper the uptake and maintenance of physical activity in frail older populations. Research suggests that seated muscle strengthening activities can be effective at improving muscle function [45-47], however, such chair-based exercise may not be feasible among very frail dependent older adults. Further, it is not known whether such interventions might be effective at altering levels of key healthy ageing biomarkers such as inflammation. The PANINI project is developing interventions to determine their feasibility and effectiveness for different frail older adult groups, including sedentary community-dwelling adults, care home residents, and hospital in- and outpatients.

\section{Prehabilitation}

The present steady increase in longevity, combined with advances in medical expertise and technologies result in an increase in invasive medical procedures, like major surgeries (e.g., abdominal surgeries or hip/knee replacements), most notably in older people [48]. These developments result in a growing demand for health care, causing rising costs and constrained resources [49]. A considerable proportion of the strain on resources is post-surgical hospitalisation, which is directly related to effective recovery from surgery. However, the ability to adequately recover from such procedures requires substantial physical and psychological resilience, which, by definition, will likely be of increased necessity with increasing age [50]. Under the umbrella of 'prehabilitation', promising new interventions are being developed that aim to increase pre-operative fitness and psychophysiological resilience/reserve capacity, even in older adults, and in this way enhance post-operative recovery [8,51] However, to adequately monitor the effects of such interventions, reliable methodologies are required that accurately and repeatedly monitor health status, not least in aged populations. This should additionally help to predict and thereby provide options to prevent eventual negative side-effects from prehabilitation.

A potentially useful example of such a methodology is the concept of allostasis [52]. Allostasis defines health status as one's ability to adapt to environmental demands by dynamic neuroendocrine responses in multiple domains, typically associated with metabolic, inflammatory, and cardio-respiratory processes. Allostasis is "achieving stability through adaptive changes" and provides an outline to quantify health, healthimpact and recovery by combining generally applied clinical (bio)markers [52,53]. Allostatic load is an index of multisystem physiological dysregulation or being in a state of allostasis [51,54]. Allostatic load is different to frailty in that it considers a range of changes which are not usually incorporated in most conceptualisations of frailty or frailty 
indices, however, multisystem dysregulation in older adults serve as a warning of developing frailty after some years [51]. Further, the present project focused on allostatic load rather than frailty because allostatic load can be observed at all ages in response to chronic or severe stress, whereas frailty indices tend to focus on changes that emerge in association with ageing itself or disease. As such, there is overlap between frailty and allostatic load in both cause and consequences, but allostatic load is broader. The 'Allostatic Load Index' (ALI) [55] is generally regarded as a valid and clinically useful parameter of resilience, most profoundly in relation to the mid- to long-term health consequences of somatic strain and psychological stress. Strangely however, the concept has so far only been validated in (quite diverse) adult populations. A validated ALI for older adults $\left(\mathrm{ALI}^{\mathrm{E}}\right)$ is yet lacking, which might be considered a serious omission, both for the patients as well as their caregivers. The explicit relevance of concepts like allostasis for specifically people "at risk" for negative health outcomes seems all too obvious. However, a seriously restrictive factor might be that some included parameters are known to change with ageing. This principle makes redesigning this concept specifically for ageing populations (e.g., in the context of prehabilitation, surgery, and recovery) quite a challenge. This endeavour has been engaged upon within the PANINI project as a first attempt to modify the ALI specifically to be applied with older adults. Using Bayesian modelling, and based on previously published statistics, preliminary results indicate that an allostatic load model specified for older people ( $>60$ years) can technically be developed (ALI ${ }^{\mathrm{E}}$ )[9]. However, this research has revealed that although the original clustering of ALI markers (neuroendocrine, immune, metabolic, cardiovascular, respiratory, and anthropometry) appears to hold in older adults very well, not all standardized (bio)markers of ALI were clustered in this age group. A possible explanation for this could be that some original (bio)markers decrease with ageing (e.g., aldosterone), significantly reducing their proportional contribution, while others seem to be too disorder-specific (e.g., dopamine in relation to dementia). Hence, in the aged population, these are not truly representative for the impact of, and recovery from, single major life events like surgery. Nevertheless, these promising new insights seem to provide useful avenues for designing effective prehabilitation protocols, strategies, and/or policies [10].

\section{Sedentary Behaviour}

As an important correlate of physical function several PANINI projects have focused on sedentary behaviour. Sedentary behaviour is defined as any waking behaviour characterized by an energy expenditure $\leq 1.5$ metabolic equivalents (METs), while in a sitting, reclining or lying posture [56]. The association between self-reported sedentary behaviour and health outcomes has been well studied [57], however, self-reported measures of physical activity tend to overestimate physical activity 
duration and intensity and underestimate sedentary time [58,59]. Consequently, PANINI aims to quantify the association between sedentary behaviour and physical function, as well as, sedentary behaviour and mortality through systematic reviews with meta-analyses.

Further, in relation to sedentary time, a series of related PANINI studies have focused on interventions to reduce sedentary behaviour in older adults, including the prehabilitation described above. We published the first systematic review to assess interventions to reduce sedentary behaviour in older adults [11]. This is despite older adults being one of the most sedentary groups within the population as well as being most at-risk for its negative health effects. Although the evidence reported in the review was limited in both quantity and quality, sedentary behaviour interventions in non-working older adults were found to have the potential to lead to meaningful reductions in sedentary time of up to 51.5 min/day. However, there was insufficient evidence for an impact of a reduction of sedentariness on clinical outcomes such as physical function and cardiometabolic health. The review informed us that future studies should be of RCT design and should endeavour to assess changes in function and health as primary outcomes, with adequate follow-up assessment to establish duration of achieved behaviour change. Additionally, it was evident few interventions on sedentariness had not been attempted in populations with mobility limitations, such as osteoarthritis. To this end, the INTEREST intervention was developed, which is an INTervention to REduce sitting Time in older adults undergoing orthopaedic surgery: a feasibility study (INTEREST) as a form of prehabilitation [12]. Working within the PANINI network has meant that it has been possible to share expertise, making the methodologies and measurement tools in projects such as INTEREST more multi-disciplinary in approach. For example, both in terms of the mixed methods needed to fully assess the feasibility of an intervention, and the incorporation of measures of psychological wellbeing and cognition alongside physical activity and physical function measures. Osteoarthritis is common to many older adults, and often results in knee or hip replacement to decrease pain and enhance quality of life [60]. While waiting for surgery, such individuals are often very sedentary, so the aim of the INTEREST project was to reduce sedentariness prior to surgery and examine whether this improved post-operative outcomes. The study was a randomised controlled trial design, with 2:1 randomisation into an intervention and usual care group respectively. Thirty-five patients aged at least 60 years or older waiting for hip and knee replacements were recruited approximately 8-10 weeks before surgery date estimates. Participants included 18 knee and 17 hip patients. Participants had a median of 3 medical conditions, indicating a high degree of multimorbidity. The Short Physical Performance Battery scores indicated great variability in physical function, and the mean BMI showed a high prevalence of overweight in the sample. Additionally, the mean self-reported daily sitting time was 8.9 
h/day and objectively measured mean sedentary time was $590.18 \pm 113.9$ mins/day (9.84 h/day). The intervention, developed using SelfDetermination Theory (SDT) [61] as a theoretical framework, was composed of multiple behaviour change techniques; namely, motivational interviewing, feedback on current objectively-measured sedentary behaviour and activity, goal-setting, environmental modification, selfmonitoring, and social support. Assessments occurred at baseline, 1-week pre-surgery, and 6-weeks post-surgery, and the intervention was of variable duration depending on patient surgery schedules. The primary outcome was the feasibility of the study and intervention, assessed quantitatively based on rates of recruitment and retention, measurescompletion, and intervention fidelity assessment, and with mixedmethods assessment of acceptability, practicality, adaption, satisfaction, and safety. Exploratory outcomes included physical function, cardiometabolic biomarkers, measurement of SDT constructs, and both objective (ActivPal inclinometers) and subjective measurement daily activity and sedentariness. Preliminary data based on $n=14$ pre-surgical assessment points in the intervention group suggests high satisfaction with the programme, with all patients stating that they were at least "likely" to keep working towards their goals in the future. However, most patients reported that achieving their goals exposed them to additional pain and was physically and mentally difficult. There was a $14.2 \%$ uptake rate, with a recruitment rate of 2.99 patients per month, highlighting the challenges to recruitment to an interventional trial among this patient group. The results of the feasibility study will be available shortly [13].

\section{Frailty}

In contrast to more able patients undergoing elective surgery, one set of projects within this physical activity work package in PANINI has specifically focussed on more frail older adults. Estimates of the prevalence of frailty in the general population vary widely [62,63], but less is known about prevalence in hospital inpatients. An ongoing output in PANINI to address this is a systematic review and meta-analysis on the worldwide prevalence of frailty amongst geriatric hospital inpatients [14]. This review is systematically searching and analysing the prevalence of frailty within geriatric hospital inpatients within the literature. If sufficient data are available, a meta-analysis synthesising pooled estimates of the prevalence of frailty and pre-frailty will be conducted [15]. Further, the prevalence of frailty stratified by age, sex, frailty definition, prevalent morbidities, ward type, and location, among older hospitalised in-patients will also be assessed. Alongside this, two specific interventions to address physical frailty have been developed as part of PANINI. One is the project Keeping Active in Residential Elderly (KARE), which is a mixed methods feasibility study presently being conducted at a care home in Birmingham, United Kingdom assessing the feasibility and impact of a sixweek adapted resistance training intervention (machine-based strength 
training). This is aimed at improving the multidimensional (physiological, psychological, cognitive, social and emotional) health and functional capacity of frail older adults within residential care settings [16]. Finally, as a similar study Seated Physical Activity in Ageing (SPAA) is ongoing, which is a mixed methods feasibility study being conducted at the Queen Elizabeth Hospital Birmingham on a ward focusing on delayed transfer of care and acute care patients. It is assessing the feasibility and impact of specialised exercise interventions (machine-based strength training and chair-based strength training) aimed at improving the multi-dimensional health and functional capacity of frail geriatric hospital inpatients [17].

The feasibility component of both KARE and SPAA is assessed through semi-structured interviews with study participants, focus groups with study support staff, a reflective journal, and analysis of recruitment and retention rates. The impact of these interventions on the multidimensional health of their respective populations is predominantly measured through physiological assessments of inflammatory markers in blood samples. Functional capacity is being measured via through hand grip strength, leg strength, Short Physical Performance Battery (SPPB)[64], Activities of Daily Living [65] and the Fried frailty phenotype assessments [42]. Psychological assessments are focussing on depression [66] and anxiety [67]. Finally, cognitive assessment is through the standardized mini-mental state examination [68] and social assessment through the Interpersonal Support Evaluation List [69]. This is a relatively novel approach within this area, with the majority of previous studies being solely concerned with the impact of such interventions on singular or bidimensional perspectives of health and well-being in the form of physiological and cognitive health, or functional capacity. It also shows the impact of developing the PANINI toolkit as a consortium and applying this across projects to take a more multi-disciplinary approach. The second novel aspect of these studies, particularly of the ongoing SPAA feasibility study, is the attempt to recruit the frailest of frail older adults with an array of comorbidities and functional deficits. These individuals would traditionally be deemed to be outside of the purview of such research.

Ageing is often accompanied by an increase in systemic inflammation, for example increases in pro-inflammatory cytokines (e.g., IL-6, TNFa), acute phase proteins (C-reactive protein) and coagulation factors (e.g., fibrinogen) [70] which are often also associated with chronic stress [71]. These can affect physical and mental function, as many diseases have common inflammatory pathogenesis such as Alzheimer's disease and arthritis. Further, stress hormone changes with ageing relate to significant decrements in immunity, mental health and frailty [72]. Thus, cortisol:dehydroepiandrosterone (DHEA) hormone ratios and inflammatory markers are being assessed within PANINI both in the context of understanding the mechanisms underlying age-related changes, and prior to and in response to novel interventions in frail older adults, such as that described above, these measures are also relevant to 
populations undergoing age-related hormonal transitions, as will be discussed in the next section.

\section{Muscle Mass, Function and Mental Wellbeing}

Good muscle function is essential for the maintenance of everyday functional capacity and quality of life. Age-related declines in muscle strength and functioning are known causes of low walking speed, mobility limitations and disabilities among older people [73]. The rate of the decline typically accelerates in later decades of life [74], however, in women the accelerated pattern may occur in midlife $[75,76]$. This difference between men and women is suggested, as mentioned above, to be due to hormonal changes occurring in menopausal years [77,78]. In addition to physiological changes, midlife has traditionally been viewed as a psychologically stressful life phase when several competing social roles, for example, caregiving and work roles, go along with a cumulative number of losses [79]. Consequently, it is important to examine whether, and how, specific physiological events, such as menopause, contribute to physical and mental well-being.

Numerous methodological issues have challenged the study of the role of menopause in muscle strength, physical functioning and mental wellbeing. These include varied criteria for distinguishing women by their menopausal status, use of a limited number of physical performance measurements not allowing for capture of different dimensions of physical fitness (e.g., muscle strength, muscle power, endurance) or focusing on negative aspects of mental well-being with insufficient attention to its positive aspects. To address these challenges, the Estrogenic Regulation of Muscle Apoptosis (ERMA) study was developed to investigate a role of menopause-related hormonal changes in physical as well as psychological functioning among 47- to 55-year old healthy women [80]. This is a population-based cohort study with both cross-sectional and longitudinal design, capturing comprehensive dimensions of physical performance, positive and negative mental well-being, and validates menopausal status by hormonal analysis. The cross-sectional part of the study in 912 participants showed that menopausal factors contribute to losing muscle strength and power as postmenopausal women were weaker by $7 \%$ in hand grip strength and, had lower muscle power by $6 \%$ than premenopausal women [18]. It was also found that physical activity plays a protective role as it helps to withstand the decline in muscle function due to menopause. The next step is to investigate the role of menopause and physical activity in mental well-being among 1098 women categorised as pre- $(n=304)$, peri- $(n=407)$ or postmenopausal $(n=387)$ based on a hormonal analysis and bleeding diary [19]. This study part captures both positive and negative dimensions of mental well-being using a depressive symptoms scale, a scale measuring positive and negative affect and a life satisfaction scale. The second part of this project is to corroborate the cross-sectional findings in a longitudinal design [20]. 


\section{Muscle Mass, Function and Health}

Particularly relevant to physical function and the onset of frailty is the health of muscle during ageing. Sarcopenia, low muscle mass and low muscle function, is an age-related condition [81] associated with adverse health outcomes [82]. In a recent PANINI systematic review and metaanalysis, a positive association between sarcopenia, falls, and fractures among older adults, independent of study design, population, sex, sarcopenia definition, continent, and study quality were found [23]. Part of the diagnostic criteria for sarcopenia is muscle strength. Hand grip strength, compared to knee extension strength, is predominantly assessed in clinical practice because of its practicality and cost. The PANINI project has found a low to moderate agreement between hand grip and knee extension strength among 960 individuals differing in age and health status [21]. Therefore, measure of a single muscle group should not be regarded as a proxy for overall muscle strength. It was also found that there were stronger associations between health characteristics and knee extension strength compared with hand grip strength among geriatric outpatients [22], suggesting additional value of measuring knee extension strength in addition to hand grip strength. Indeed, this broader approach has been then applied in studies within the Physical Activity work package within PANINI such as the KARE and INTEREST projects.

Nutrition plays an important role in physical function and counteracting sarcopenia, which is where the physical activity and nutrition work packages within PANINI overlap. To establish dietary goals, knowledge of individual energy requirements is required. Recent studies indicated that resting metabolic rate is increased by chronic diseases in older adults independent of body composition [83,84]. A study is currently being conducted within PANINI [26] to better understand the association between number, severity and types of diseases with resting metabolic rate among geriatric outpatients. Indirect calorimetry is the preferred method to determine resting metabolic rate. Metabolic monitoring devices such as QUARK are however relatively expensive, less portable and complicated to calibrate and use, thus routine resting metabolic rate measurement is difficult and impractical in clinical practice. Fitmate GS is a new portable device, easier to calibrate, requires less space, less training for operators and has lower operational costs. However, both metabolic monitoring devices have not yet been investigated in the same individuals. It was found that there was good relative agreement of resting metabolic rate between Fitmate GS and QUARK indirect calorimetry measures of resting metabolic rate in healthy adults [24]. In the absence of a gold standard, Fitmate GS is recommended because of price and practical advantages.

Finally, early diagnosis and subsequent intervention of sarcopenia requires awareness among healthcare professionals. Limited knowledge about sarcopenia was identified among 250 healthcare professionals in Australia and New Zealand attending a professional development event- 
the "Sarcopenia Roadshow" [25]. Next to educational strategies, this study identified practical issues that need to be resolved to overcome barriers in diagnosing and treating sarcopenia.

\section{Ageing in the Era of Personalized Medicine}

In order to integrate the ongoing research above on the impact of ageing, nutrition and physical activity on muscle strength and function, one set of projects within PANINI focused on the metabolic processes underlying muscle ageing. Dysregulation of mitochondrial function in the muscle is a hallmark of ageing and age- and lifestyle-related diseases and so within PANINI it is being studied in skeletal muscle, applying a systems biology approach. Biomedical research is becoming more and more a datadriven process: the last decades saw a surge in the generation of data from high-throughput experiments (e.g., DNA and RNA sequencing, proteomics), clinical records and wearable devices. Computational models of human physiology, such as genome-scale metabolic models, offer a context to interpret experimental and clinical data and a framework to test new hypotheses, thus guiding the planning of new experiments [85].

Thus far, a collection of age-specific computational models of muscle metabolism from gene expression data have been developed. These models allow the computational study of the age-related reprogramming of muscle metabolism. Acting as simulated patients, these models facilitate integration and interpretation of multiple types of molecular data (genetic, proteomic, gene expression), providing structured a priori knowledge on how the different biological systems interact. During the development of these models it became clear that existing tools were not sufficient to investigate the metabolic heterogeneity across individual metabolic models. Starting from the concept of distance metrics between genomescale metabolic models, we introduced a framework to enable the application of machine learning algorithms to large collections of metabolic models [27] allowing to search for patterns in hundreds of models at the same time.

Machine learning tasks such as clustering and classification, are becoming relevant in the emerging field of personalized medicine: they have already been used for patient stratification, to enable the discovery of previously unknown disease sub-types, and to provide indications for diagnosis and targeted therapeutic treatments. The application of such algorithms to datasets containing up to hundreds of metabolic models, brings together physiology-based mechanistic models and statistical analysis of large datasets. Such have been derived in part from partners within the Nutrition work package who have access to clinical and experimental datasets, to identify the metabolic processes involved in muscle ageing and help develop personalized anti-ageing treatments.

Computational modelling and statistical tools such as pattern recognition algorithms are also going to be a fundamental part of medicine in the near future, helping the diagnosis of diseases and offering 
indications for tailored medical treatments. In another ongoing PANINI project, statistical models and machine learning are being applied also to the EMPOWER data [28]. This study, conducted by one of the PANINI partners, the VU Medical Center in Amsterdam, explores the association between muscle mass and strength in a cohort of older adults at hospital admission, and the incidence of four geriatric conditions (delirium, malnutrition, falls and loss of independence in daily activities) for each individual [86]. From these data a multivariate logistic regression model has been created to predict the chance of survival and of living independently for frail older adult inpatients, three months after hospital discharge. This is an example of cross-network collaboration and integration of the impact of nutrition and physical activity on healthy ageing in existing cohorts that would not be possible without the network. Finally, the tools developed so far will be applied to the shared PANINI dataset, a heterogeneous set of clinical, biological, physical activity, nutrition, cognition and psychological data derived from the PANINI projects, to investigate the relation between physical activity, nutrition and the pace of ageing.

\section{WORK PACKAGE 3: NUTRITION}

Human ageing is typically associated with a gain in fat mass (adiposity), which with decreased activity can contribute to sarcopenia, and reduced mobility [87]. However, with ageing, energy intake also decreases, and under-nutrition is prevalent, particularly in hospitals and geriatric outpatients, yet correct nutrition and physical activity engagement can enhance quality of life, cognition, muscle mass, and decrease fat. PANINI is assessing nutritional intake, physical activity and health outcomes in a range of older populations including frail outpatients, and associations between malnutrition and specific aspects of physical function have been demonstrated in the ongoing projects above. This knowledge can also be used to develop and test interventions to counteract frailty. Much of the research on the broad-reaching effects of diet and nutrition that is published in the general media is contradictory. Controversial findings on the impact of diet on age-related cognitive function might be explained by a combination of short- and long-lasting effects that cannot always be captured by neurocognitive tests [88,89]. Besides neurocognitive testing, neuroimaging studies have provided evidence that nutrients influence brain imaging measures. For instance, alterations of the cerebral blood flow, brain metabolism, functional connectivity and integrity of the white matter have been associated with specific nutrients [89-91]. However, the study of dietary patterns better reflects the interactions between the different nutrients of a diet. Consequently, within PANINI a systematic review focusing on the impact of dietary patterns on brain imaging measures and cognition was conducted [29]. Results seem to indicate that dietary patterns correlate with alterations in specific brain imaging correlates, cognition or both. 
As previously found on the SW/TEMPO cohort, a community-based prospective cohort aiming to understand healthy ageing, lifestyle factors such as physical activity positively correlate with the cognitive performance in older community-dwelling adults [92]. The cognitive performance of the participants was derived from a comprehensive neuropsychological battery of tests assessing executive and memory functions. More specifically, response inhibition/cognitive flexibility was measured with Stroop colour-word test [93] verbal fluency with the controlled oral word association test F-A-S [94], and high level information processing speed with the digit symbol substitution test (DSST, subtest of the Wechsler adult intelligence test WAIS III, 1997)[93]. As for the memory domain, the digit span forward test (subtest of the Wechsler adult intelligence test WAIS III, 1997) measured short-term verbal memory [95], the digit span backward test (subtest of the Wechsler adult intelligence test WAIS III, 1997) ascertained verbal working memory [95] and the selective reminding test assessed verbal learning [96]. General cognitive status was ascertained with the mini-mental state examination [97]. In the same cohort, it was hypothesised that another factor could impact on agerelated cognitive performance-a healthy diet. The ongoing analyses indicate that that the previous adherence to a Mediterranean-like diet, as assessed by the Mediterranean Diet Adherence Score (MEDAS)[98], is associated with executive and memory composite scores [31]. Interestingly, structural and functional alterations of the prefrontal cortex (PFC), a brain area involved in the dietary self-regulation, were associated with body mass index (BMI)[99]. Similarly, preliminary analyses suggest that structural brain changes were associated with adherence to the Mediterranean diet [32]. Moreover, in a longitudinal analysis, functional status as measured by the Lawton Instrumental Activities of Daily Living questionnaire [100] is correlated with adherence to the Mediterranean diet [30].

Despite the mounting evidence of the benefits of a healthy dietary pattern, adherence to a healthy diet is poor and behaviour change difficult. Several factors have been reported to hamper behaviour change from the patient's perspective. Food preferences, lack of cooking skills, limited budget, low education attainment and lack of understanding of dietary recommendations were reported to impact behaviour change [101,102]. While educational interventions did not always lead to a sustainable behaviour changes [103], collaborative clinical methods such as motivational interviewing yielded promising results [104]. Thus, within PANINI it was hypothesized that a motivational interviewing-based approach to dietary counselling would be more effective in changing older adults' eating habits than the traditional approach. Currently, this intervention is taking place at primary care centres in Portugal [29-32]. This is an example of the links between the physical activity work package projects developing interventions and the nutritional work package. Shared expertise and training promoted incorporation of different 
methodologies across projects where these techniques were not currently in use.

It is not just adherence to diet that is challenging, but indeed the assessment of dietary intake itself. Assessing dietary intake is subject to bias yet quantitative methods are cost- and labour-intensive and only provide a narrow view of nutrients [105]. PANINI is also extending beyond nutritional intake alone by using a mixed-methods approach that can provide a richer and broader view of food choice and eating behaviours, allowing the possibility of designing appropriate interventions that address and sustain healthy food choices in older age.

Within PANINI, a longitudinal, observational, mixed methods study of community-dwelling ethnically diverse older adults aged 60 years and older living in Birmingham, UK has taken place. Many ethnic minority groups live in areas of higher deprivation and experience disproportionate health inequalities, predisposing them to a lower quality of life and poorer health than the White British population. One study aimed to explore the social networks, nutrient intake, nutritional status and physical function among this population over an 8-month period using a concurrent mixed methods design [33,34,36]. Additionally, the study sought to measure how any changes in social networks impacted on these variables throughout this time period.

The study recruited 100 participants self-identifying as Africans/Caribbean (58\%), South Asians (34\%), and other ethnicities (7\%) with a mean age (SD) of 70.8 (8.1). Five social network typologies were identified using the Wenger Practitioner Assessment of Network Types (PANT)[106]: locally integrated (44\%), family dependent (25\%), locally selfcontained (16\%), wider community (8\%) and private restricted (6\%). Locally integrated and wider community social networks were combined to form the category, "integrated social network", while the remaining three formed the "non-integrated social network". Nutrient intake was measured using multiple pass 24-h dietary recalls. In line with the PANINI toolkit of best practice measures, nutritional status was measured using the Mini Nutritional Assessment-Short Form (MNA-SF)[107]. Physical function was measured using the Short Physical Performance Battery (SPPB)[33] and hand grip strength test. At follow-up, 81 participants provided complete data, with a mean age (SD) of 70.7 (8.2), composed of $35 \%$ females.

There were three main findings from this study [35]. First, social networks changed over the eight months, which was associated with changes in nutritional status and physical function at follow-up. At baseline, integrated social networks as compared to non-integrated social networks were found to predict lower declines in physical function and a lower risk of malnutrition at follow-up. These results were also supported by the qualitative findings, as participants identified that declines in their social networks combined with other factors had a negative impact on their physical function and eating behaviours. 
Second, there was a significant association between nutrient intake, nutritional status, and physical function over time. There were significant decreases in intakes of vitamin B6, vitamin B1, iron, folate, and magnesium. Despite these declines, the intakes of these nutrients, except for folate, were still above the UK Recommended Nutrient Intake (RNI) values at follow-up. However, when these intakes were controlled for energy intake, the resultant intakes of these were below the RNI. A healthier nutritional status was associated with higher physical function at baseline and follow-up.

Finally, perceptions of, and factors influencing, healthy eating and physical function were shaped by various socio-demographic characteristics and the presence of non-communicable diseases. Perceptions of healthy eating were related to portion sizes, eating patterns and cooking methods. Physical function was perceived as "fitness" and the ability to carry out activities of daily living. The majority viewed healthy eating as more important than, and unrelated to, physical function. The most common factors influencing eating behaviours and physical function were medical conditions, age, religion/faith, body image, diversity, social support, and cultural beliefs and practices. At follow-up, males were more likely to report experiencing negative changes in their lives, including declines in social support, illness, and issues with the weather, and more commonly identified these as negatively affecting eating behaviours and physical function than female participants. Overall, the findings of this study will contribute to the growing evidence of providing critical insights to inform programmes and approaches that can be used to improve health among ethnically diverse older adults.

\section{GENETICS AND EPIGENETICS}

Pulling together the work packages across PANINI, we have also sought to discover biomarkers able to predict the biological age of an individual as a crucial goal of ageing research. Various epigenetic markers are relevant to this and are being investigated in terms of their ability to predict physiological function independently of age. This could, for example, be used to test the effectiveness of different nutritional and physical function interventions at modulating important epigenetic markers. In addition, the PANINI network has also been exploring the relevance of individual genetic background for the development of sarcopenic/frail phenotypes and for the success of nutritional and physical activity interventions within PANINI, in this way linking methodologies and underlying mechanisms across the network.

Heritable reversible changes in chromatin structure and gene function, which can be used to determine biological ageing and health, are called epigenetics. Certain genes show increases in methylation across the lifespan so can be considered to be potential biomarkers of ageing [108]. The discovery of these so-called 'epigenetic clocks' represents important progress in the field of ageing research within the last six years [109-111]. 
As their names imply, these biomarkers are based on epigenetics, and more specifically on DNA methylation. DNA methylation consists in the addition of a methyl group to a cytosine residue, preferentially in a CpG dinucleotide. Epigenetic clocks are mathematical models which combine DNA methylation levels at specific CpG sites in order to estimate one individual's age. They are considered as robust measures of chronological age, but they are also great indicators of the biological age of a subject [112]. Several lines of evidence have suggested that the epigenetic age predictors can be influenced by lifestyle factors, among which are nutritional variables. Within the framework of the PANINI project, there was the objective of studying the impact of nutritional and physical interventions on epigenetic biomarkers of age. Firstly, the influence of a one-year Mediterranean-like diet was evaluated, delivered within the framework of the NU-AGE project [113] on Horvath's clock, a mathematical model which combines DNA methylation values at $353 \mathrm{CpG}$ sites in order to estimate the biological age of an individual, and three derived measures of epigenetic age acceleration [109,111], named AgeAcceleration, Intrinsic Epigenetic Age Acceleration (IEAA) and Extrinsic Epigenetic Age Acceleration (EEAA) [37,38]. These measures are aimed at capturing different aspects of biological ageing, as IEEA is independent of blood cell type dynamics while EEAA appears to be more informative of immune system ageing. Secondly, it was a goal to develop a new epigenetic biomarker of ageing, based on a gene-targeted DNAm analysis. This biomarker of age, based on the combination of a limited number of $\mathrm{CpG}$ sites carefully chosen after literature review and exploitation of available datasets, is assessable through the EpiTYPER assay. This new epigenetic biomarker will soon be applied to samples newly collected within the PANINI project, in order to monitor the impact of physical activity interventions, thereby maximising potential via the links across the PANINI network.

Research into genes underlying differences in muscle mass or muscle strength has shown different sarcopenia risk phenotypes. However, a less studied but relevant field is that of the relationship between nutritional habits and variants in genes that affect appetite and dietary preferences. PANINI is novel in addressing this little studied area; by examining the interplay between genetic background, diet and sarcopenic/frail phenotype in older adults.

Medical genomics has the objective to translate high throughput genetic methods to the clinic, aiming to interpret the clinical significance of genetic variants present in an individual genome. Next Generation Sequencing (NGS) technologies are rapidly becoming a routine in diagnostics and screening tests as an alternative to chips genotyping, able to detect the presence or absence of genetic variants only at single positions along the human genome.

Targeted resequencing is a common application for NGS technologies, which allows the capture and sequencing of selected regions of interest 
(ROI) of the genome. This methodology improves the process of base calling (genotyping) at single sites extending it to the entire ROI sequence. Sequencing fragment length is generally suggested by standard protocols of library preparation. The DNA library represents a collection of similarly sized fragments aimed to be sequenced through a selected platform to generate a set of reads. The reads will be eventually mapped to known reference bases of the human genome to identify their correct location along it. Variant sites compared to the reference genome are identified and reported in a VCF file, the most used standard format, which is quite limited due to the lack of information about the invariant genomic regions (same as reference). Positions not reported in a VCF file can be reference or not genotyped due to limitations of the technology. For this reason, the absence of a genetic variant in a specific position could lead to an incorrect interpretation.

The most common parameter used to indicate whether a genomic position could be properly genotyped is the depth of coverage, or the average number of reads that map on the region of interest [114]. Nevertheless, the successful base calling (genotypability) has been observed to be influenced not only by the number of reads mapping in a specific region, but also by other parameters like the quality of the read alignment, determined on the base of its uniqueness. Repeated or highly homologous regions of the genome usually lead to a low-quality mapping, where no high-confidence variant discovery can be performed. For this reason, in order to optimize the genotypability of the ROI, the enhancement of the quality of the read alignment is necessary.

The aim of this work within PANINI was to optimize the genotypability of the ROI through the optimization of the library length, whose extension may overcome the repeated or homologous portions of the genome for the achievement of a higher quality mapping. Accordingly, targeted resequencing of the human genes was performed on three unrelated individuals using three different library lengths: standard protocol length (200-250 bp), $350 \mathrm{bp}$ and $500 \mathrm{bp}$. Through the setup of a bioinformatic pipeline and by taking advantage of the gVCF file format, an extension of the VCF that reports the genotypes of both variant and reference sites and their associated calling scores, the genotypability of the ROI was calculated and compared for each library length. Results have shown that the library length influences the genotypability of the ROI.

In the context of the PANINI project, one aim is to address the need to identify genetic markers for ageing diseases and nutritional responses, this methodology can provide the genotypability performance of a custom panel designed on regions of interest focused on these markers. According to the project's objectives, the identification of the ROI was undertaken through a comprehensive literature research integrating Single Nucleotide Polymorphisms (SNP) associated with nutrition and ageing. SNPs associated with ageing have been collected from genome-wide association studies of different cohorts of long-lived individuals and 
centenarians, through the research of the word "longevity" in the GWAS database. SNPs associated with nutrition have been obtained from the NUAGE project performing an association study on the change in the epigenetic clock of samples after dietary intervention. Therefore, the best performing custom panel has been selected on the base of the performance on the ROI [39], with the aim of sequencing a limited selection of samples for the high-confident identification of genetic variants. This work will provide an improved evaluation of the sequencing data obtained within the PANINI project.

\section{LIMITATIONS}

One of the limitations of the PANINI consortium is that some of the projects are relying on secondary analysis of existing data. While this gives a rich source of data unlikely to be able to be collected within the lifetime of PANINI, it does mean that our standardised measures are not consistent across all of the studies involved in PANINI, and not all datasets contributing to PANINI were directly comparable. Nor was it possible for samples to be donated for analysis such as epigenetics or genomics where these prior studies were less recent or did not take or store blood samples. However, loss of existing data would limit the analyses that have been possible in different population groups and limit the possibility of using machine learning approaches. Further, the existing datasets and network partners working on them helped drive the selection of the best practice but pragmatic, i.e., feasible and commonly used, toolkit of measures. A further limitation was that in some of the new data collection it was not feasible to incorporate all of the PANINI toolkit measures, for example, where data collection was qualitative in focus and additional nutrition measures would have provided too much participant burden but not much further information. However, there were enough common measures across the network to ensure data combining and analysis for all partners, thus achieving more as a network than single projects would. Future collaborations might consider either only incorporating new data collection and consistency of measures across all studies for greater comparability, or accept that a rich range of existing and new data restricts data combining somewhat. Finally, it should be acknowledged that our specific focus on nutrition and physical activity in ageing meant that the measurement of psychological, social, and cognitive factors was not analysed in depth. However, the use of the standardised toolkit, and a multi-disciplinary approach as well as the greater depth of cognitive and psychological assessment in some of the existing datasets contributing to PANINI does mean that these factors were considered and assessed in some of the PANINI projects. This contributes to our knowledge and understanding of how all of these important factors interact to predict healthy ageing. Future collaborations may also wish to integrate socioeconomic and other environmental factors into their assessment and modelling of contributors to healthy and unhealthy ageing. 


\section{FUTURE DIRECTIONS AND CLINICAL RELEVANCE}

Given the emerging evidence presented above, some clear future directions based on the PANINI project have been identified. Understanding which (bio)markers cluster in older age groups would seem essential to further develop the potential of the outlined ALI ${ }^{\mathrm{E}}$. The work on sedentary behaviour revealed that future interventions should be of RCT design and should endeavour to assess changes in function and health as primary outcomes, with adequate follow-up assessment to establish duration of achieved behaviour change. The feasibility studies within PANINI are showing that very little research has attempted to recruit the frailest of frail older adults with range of functional deficits. However, it is these individuals who may actually benefit the most from such interventions if they are found to be feasible, therefore future studies should seek to engage frailer difficult to reach populations. Further, the work in midlife adults shows the impact of key life transitions such as hormonal changes due to the menopause and its interaction with physical activity in the prediction of physical function and mental wellbeing. This underlines the need to assess wellbeing multi-factorially in terms of biological, psychological and functional aspects of health. In line with multiple measurements, the research into sarcopenia suggests a much broader picture of strength in older age interactions with health will be developed through measuring knee extension strength in addition to hand grip strength. Further, this line of research suggested that there should be a greater focus on educating health professionals on what sarcopenia is to improve its diagnosis and treatment. With regard to improving dietary patterns for overall health including cognition, PANINI is testing whether a motivational interviewing-based approach is more effective in changing dietary habits than the traditional educational strategies. Future studies should focus on approaches to facilitating behaviour change so that older adults benefit from more successful ageing. Similarly, the findings from the mixed-methods study of nutrition and physical activity in diverse ethnic groups should inform the design of new, and adaptation of existing, culturally tailored community interventions to support healthy ageing among this population. Further, based on the development and testing of new epigenetic biomarkers of ageing, future research will be able to implement these measures into bigger cohorts to gain deeper insight into the biological impact of healthy ageing nutritional and/or physical activity interventions. In a related manner, the identification of genetic markers for nutritional responses in ageing is relatively new, but this methodology can provide improved evaluation of sequencing data in future research to better understand the interaction between genetics and lifestyle factors in the prediction of healthy ageing. Bringing together the different measurements collected in studies such as PANINI, and through the use of a standardised toolkit, means that machine learning tasks, such as clustering and classification, can be applied for the integrative analysis of heterogeneous datasets such as the PANINI Shared Dataset. If future 
research contributes multiple measurements including genome and epigenetic data to the acquisition of big datasets on healthy ageing, systems biology approaches could be used more accurately to provide indications for diagnosis and targeted therapeutic treatments.

\section{CONCLUSIONS}

In summary, the PANINI project has been addressing the impact of physical activity and nutrition on healthy ageing from a range of diverse but interlinked perspectives. First, using standardized best practice measures as far as possible the consortium has developed a shared dataset of physical, cognitive and psychological function and nutritional status measures across a range of older adult populations in order to compare these across different settings including hospital inpatient, outpatient, care home and community-dwelling older adults. Thus far it has been used to examine the association between malnutrition and a range of physical function measures. Second, PANINI has conducted or is conducting extensive literature reviews on relevant topics such as frailty prevalence, sedentary behaviour prevalence, sedentary behaviour and physical function, dietary pattern impact on cognition and brain imaging measures, and the impact of interventions to reduce sedentariness. Combining datasets and sharing data from existing and new PANINI projects has also allowed the development and testing of key epigenetic and genetic markers of ageing, as well as assessing whether these might be useful predictors of intervention success, which is a next step. This data sharing also allows for computational modelling of the contribution of factors such as genetics and muscle metabolomics to muscle function, frailty progression and survival. Further, we have been able to develop and/or test nutritional and physical activity interventions in a range of settings and older adult populations in terms of their impact on cognitive, psychological, social, and physical function measures, leading to conclusions regarding the feasibility of such interventions as well as the impact of intervention adherence. Factors predicting knowledge of, adherence to and choice of different dietary and physical activity advice have also been explored in more detail, providing vital information regarding the potential targets for intervention and policy guidance. As such, the PANINI project has brought together a diverse and multidisciplinary range of projects to contribute to our understanding of predictors of healthy and unhealthy ageing thus far, and is set to reveal more about these as the projects conclude and form part of the planned shared dataset, which will latterly be made open access for other researchers into ageing processes to interrogate.

\section{CONFLICT OF INTEREST}

The authors declare no known conflict of interest. 


\section{FUNDING}

This project has received funding from the European Union's Horizon 2020 research and innovation programme under the Marie SkłodowskaCurie grant agreement No 675003. http://www.birmingham.ac.uk/panini.
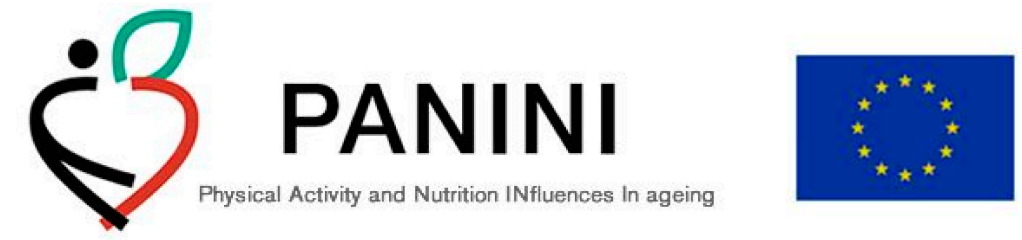

\section{REFERENCES}

1. Department of Economic and Social Affairs, United Nations. World Population Ageing. New York (US): United Nation; 2015. Report No. ST/ESA/SER.A/390.

2. Whittaker AC, Delledonne M, Finni T, Garagnani P, Greig C, Kallen V, et al. Physical Activity and Nutrition INfluences In ageing (PANINI): consortium mission statement. Aging Clin Exp Res. 2018;30(6):685-92. doi: 10.1007/s40520017-0823-7

3. Whittaker A. Lengthening healthy life: the PANINI project. Impact. 2017;2017:60-2.

4. Whittaker A. Physical Activity and Nutrition Influences In ageing: PANINI. Open Access Gov. 2018;2018:46-7.

5. Ramsey KA, Meskers CGM, Trappenburg MC, Whittaker AC, Maier AB. Physical Activity and Nutritional INfluences In Ageing (PANINI) Toolkit: A Comprehensive Geriatric Assessment. 2019. Unpublished work.

6. Ramsey KA, Meskers CGM, Trappenburg MC, Verlaan S, Reijnierse EM, Whittaker AC, et al. Malnutrition is associated with dynamic physical performance. 2019. Unpublished work.

7. Ramsey KA, Yeung SY, Rojer A, Gensous N, Asamane EA, Aunger JA, et al. Is Knowing Better Doing Better? The relationship between knowledge of nutrition and physical activity guidelines and physical function and activity in older adults. 2019. Unpublished work.

8. Thomas MG, Tahir M-R, Bongers BC, Kallen VL, Slooter GD, van Meeteren NLU. A systematic review of randomised controlled trials investigating prehabilitation before major intra- abdominal cancer surgery An analysis of prehabilitation content and outcome measures. 2019.p 15. Unpublished work.

9. Tahir M-R, Kallen VL, Bedard A, Bongers BC, N.L.U. van M. AGING \& ALLOSTASIS: A critical evaluation of allostatic markers in the context of aging. 2019. Unpublished work.

10. Tahir M-R, Kallen VL, Bongers BC, van Meeteren NLU. Capturing changes in functional, inflammatory and metabolic biomarkers over time in elderly undergoing major (abdominal) surgeries. 2019. Unpublished work.

11. Aunger JA, Doody P, Greig CA. Interventions targeting sedentary behavior in non-working older adults: a systematic review. Maturitas. 2018;116:89-99.

12. Aunger JA, Greaves CJ, Davis ET, Greig CA. A novel behavioural INTErvention 
to REduce Sitting Time in older adults undergoing orthopaedic surgery (INTEREST): protocol for a randomised controlled feasibility study. Pilot Feasibility Stud. 2019 Dec 6;5(1):54.

13. Aunger JA, Greaves CJ, Davis ET, Asamane EA, Whittaker AC, Greig CA. A novel behavioural INTErvention to Reduce Sitting Time versus usual care in older adults undergoing orthopaedic surgery (INTEREST): results of a randomised controlled feasibility study. 2019. Unpublished work.

14. Doody P, Aunger JA, Asamane EA, Greig CA, Lord JM, Whittaker A.C. Frailty Levels in Geriatric Hospital paTients (FLIGHT) - The prevalence of frailty amongst geriatric populations within hospital ward settings: A systematic review protocol. BMJ Open. 2019. Submitted for publication.

15. Doody PD, Asamane EA, Aunger JA, Swales B, Greig CA, Lord JM, et al. Frailty Levels In Geriatric Hospital paTients (FLIGHT) - the worldwide prevalence of frailty amongst geriatric hospital inpatients and its association with healthcare expenditure and economic prosperity: A systematic review and meta-analysis. 2019. Unpublished work.

16. Doody P, Lord JM, Whittaker AC. Assessing the feasibility and impact of an adapted resistance training intervention, aimed at improving the multidimensional health and functional capacity of frail older adults in residential care settings: protocol for a feasibility study. Pilot Feasibility Stud. Forcoming 2019.

17. Doody P, Lord JM, Greig CA, Whittaker AC. Assessing the feasibility and impact of specially adapted exercise interventions, aimed at improving the multi-dimensional health and functional capacity of frail geriatric hospital patients: protocol for a feasibility study (SPAA). Pilot Feasibility Stud. 2019;

18. Bondarev D, Laakkonen EK, Finni T, Kokko K, Kujala UM, Aukee P, et al. Physical performance in relation to menopause status and physical activity. Menopause. 2018;25(12):1432-41.

19. Bondarev D, Sipilä S, Finni T, Kujala U, Aukee P, Laakkonen E, et al. The role of physical activity in the link between menopausal status and mental wellbeing. 2019. Unpublished work.

20. Bondarev D, Finni T, Laakkonen E, Kokko K, Kujala U, Aukee P, et al. Changes in the physical performance and a role of physical activity during menopausal transition. 2019. Unpublished work.

21. Yeung SSY, Reijnierse EM, Trappenburg MC, Hogrel J-Y, McPhee JS, Piasecki M, et al. Handgrip Strength Cannot Be Assumed a Proxy for Overall Muscle Strength. J Am Med Dir Assoc. 2018;19(8):703-9.

22. Yeung SSY, Reijnierse EM, Trappenburg MC, Blauw GJ, Meskers CGM, Maier $\mathrm{AB}$. Knee extension strength measurements should be considered as part of the comprehensive geriatric assessment. BMC Geriatr. 2018;18(1):130.

23. Yeung SSY, Reijnierse EM, Pham VK, Trappenburg MC, Lim WK, Meskers CGM, et al. Sarcopenia and its association with falls and fractures in older adults: A systematic review and meta-analysis. J Cachexia Sarcopenia Muscle. 2019. doi: 10.1002/jcsm.12411

24. Yeung SY, Trappenburg MC, Meskers CGM, Maier AB, Reijnierse EM. The use of a portable metabolic monitoring device for measuring resting metabolic 
rate in healthy young and older adults. 2019. Unpublished work.

25. Yeung SY, Reijnierse EM, Trappenburg MC, Meskers CGM, Maier AB. Current knowledge and practice of Australian and New Zealand healthcare professionals in sarcopenia diagnosis and treatment: Time to move forward! 2019. Unpublished work.

26. Yeung SY, Reijnierse EM, Trappenburg MC, Meskers CGM, Maier AB. Clinical determinants of resting metabolic rate in geriatric outpatients. 2019. Unpublished work.

27. Cabbia A, Hilbers PAJ, van Riel NAW. Distance metrics for genome scale metabolic networks. 2019. Unpublished work.

28. Cabbia A, Hilbers PAJ, Maier AB, van Riel NAW. A machine learning model to predict 3-month mortality and the chance of living independently three months after hospital discharge. 2019. Unpublished work.

29. Rodrigues B, Asamane EA, Sousa N, Thompson JL, Correia Santos N. The impact of dietary patterns on cognition through the lens of neuroimaging-a systematic review. 2019. Unpublished work.

30. Rodrigues B, Portugal-Nunes C, Magalhães R, Costa Castanho T, Marques P, Miguel Soares J, et al. The interplay between diet quality and cognitive performance on physical functioning in healthy aging. 2019. Unpublished work.

31. Rodrigues B, Portugal-Nunes C, Coelho A, Silva Moreira P, Costa Castanho T, Amorim L, et al. Study on the Mediterranean diet affects cognition and brain measures in community dwelling adults. 2019. Unpublished work.

32. Rodrigues B, Portugal-Nunes B, Costa Castanho T, Amorim L, Sousa N, Correia Santos N. The relationship between healthy diet and self-control brain areas. 2019. Unpublished work.

33. Asamane EA, Greig CA, Thompson JL. Social networks and their influences on dietary intake, nutritional status and physical function of communitydwelling ethnically diverse older adults: A mixed method longitudinal study. 2019. Unpublished work.

34. Asamane EA, Greig CA, Thompson JL. The association between nutritional status, cognition and physical function of community-dwelling ethnically diverse older adults: A longitudinal study. 2019. Unpublished work.

35. Asamane EA, Greig CA, Aunger JA, Thompson JL. Perceptions and Factors Influencing Eating Behaviours and Physical Function in Community-Dwelling Ethnically Diverse Older Adults: A Longitudinal Qualitative Study. Nutrients. 2019 May 29;11(6):1224.

36. Asamane EA, Ferreira-Rodrigues B, Sousa N, Correia Santos N, Thompson JL. The interplay of dietary fibre and social networks on cognition among community-dwelling older adults: A moderation model. 2019. Unpublished work.

37. Gensous N, Garagnani PAS, Giuliani C, Ostan R, Fabbri C, et al. One-year Mediterranean-diet promotes epigenetic rejuvenation in the elderly participants of the NU-AGE study: country and sex-specific effects. 2019. Unpublished work.

38. Gensous N, Bacalini MG, Franceschi C, Meskers CGM, Maier AB, Garagnani P. 
DNA methylation and skeletal muscle aging in humans. 2019. Unpublished work.

39. Iadarola B, Xumerle L, Lavezzari D, Paterno M, Marcolungo L, Beltrami C, et al. Enhanced targeted resequencing by optimized combination of enrichment technology and DNA insert length. 2019. Unpublished work.

40. Engelheart S, Brummer R. Assessment of nutritional status in the elderly: a proposed function-driven model. Food Nutr Res. 2018;62. doi: 10.29219/fnr.v62.1366

41. Fávaro-Moreira NC, Krausch-Hofmann S, Matthys C, Vereecken C, Vanhauwaert E, Declercq A, et al. Risk Factors for Malnutrition in Older Adults: A Systematic Review of the Literature Based on Longitudinal Data. Adv Nutr. 2016;7(3):507-22.

42. Fried LP, Tangen CM, Walston J, Newman AB, Hirsch C, Gottdiener J, et al. Frailty in older adults: evidence for a phenotype. J Gerontol A Biol Sci Med Sci. 2001;56(3):M146-56.

43. Chastin SFM, Buck C, Freiberger E, Murphy M, Brug J, Cardon G, et al. Systematic literature review of determinants of sedentary behaviour in older adults: a DEDIPAC study. Int J Behav Nutr Phys Act. 2015 Dec 6;12(1):127.

44. Bongers BC, Dronkers JJ, Hulzebos EHJ, Hoogeboom TH, Buhre WF, van Meeteren NLU. Optimizing perioperative physical therapy care in major elective surgery to improve surgical outcome in high-risk patients: the Better in, Better outTM concept. 2016. Available from: bartbongers.com/wpcontent/uploads/2017/04/Bongers-et-al.-2016-Better-in-Better-out-NTvA.pdf. Accessed 2019 Jun 12.

45. Anthony K, Robinson K, Logan P, Gordon AL, Harwood RH, Masud T. Chairbased exercises for frail older people: a systematic review. Biomed Res Int. 2013;2013:309506.

46. Castrogiovanni P, Musumeci G, Castrogiovanni P, Musumeci G. Which is the Best Physical Treatment for Osteoarthritis? J Funct Morphol Kinesiol. 2016 Jan 28;1(1):54-68.

47. Castrogiovanni P, Di Rosa M, Ravalli S, Castorina A, Guglielmino C, Imbesi R, et al. Moderate Physical Activity as a Prevention Method for Knee Osteoarthritis and the Role of Synoviocytes as Biological Key. Int J Mol Sci. 2019;20(3).

48. Siegel R, Naishadham D, Jemal A. Cancer statistics for Hispanics/Latinos, 2012. CA Cancer J Clin. 2012 Sep;62(5):283-98.

49. Dindo D, Demartines N, Clavien P-A. Classification of surgical complications: a new proposal with evaluation in a cohort of 6336 patients and results of a survey. Ann Surg. 2004 Aug 1;240(2):205-13.

50. Tan K-Y, Konishi F, Tan L, Chin W-K, Ong H-Y, Tan P. Optimizing the management of elderly colorectal surgery patients. Surg Today. 2010 Nov 3;40(11):999-1010.

51. Gruenewald TL, Seeman TE, Karlamangla AS, Sarkisian CA. Allostatic Load and Frailty in Older Adults. J Am Geriatr Soc. 2009 Sep;57(9):1525-31.

52. Juster R-P, McEwen BS, Lupien SJ. Allostatic load biomarkers of chronic stress and impact on health and cognition. Neurosci Biobehav Rev. 2010 Sep;35(1):2- 
16.

53. Seeman T, Gruenewald T, Karlamangla A, Sidney S, Liu K, Mcewen B, et al. Modeling multisystem biological risk in young adults: The Coronary Artery Risk Development in Young Adults Study. Am J Hum Biol. 2009 Dec 28;22(4):463-72.

54. Sterling P. Principles of allostasis: optimal design, predictive regulation, pathophysiology and rational therapeutics. In: Schulkin J, editor. Allostasis, homeostasis and the costs of adaptation. Cambridge (UK): Cambridge University Press; 2004.

55. Juster R-P, Sindi S, Marin M-F, Perna A, Hashemi A, Pruessner JC, et al. A clinical allostatic load index is associated with burnout symptoms and hypocortisolemic profiles in healthy workers. Psychoneuroendocrinology. 2011;36(6):797-805.

56. Network S, Research B. Sedentary behaviour research network. 2012. Standardized use of the terms sedentary and sedentary behaviours. Appl Physiol Nutr Metab. 2012;540-2.

57. Rezende LFM de, Rodrigues Lopes M, Rey-López JP, Matsudo VKR, Luiz O do C. Sedentary Behavior and Health Outcomes: An Overview of Systematic Reviews. Lucia A, editor. PLoS One. 2014 Aug 21;9(8):e105620.

58. Ryan DJ, Wullems JA, Stebbings GK, Morse CI, Stewart CE, Onambele-Pearson GL. Reliability and validity of the international physical activity questionnaire compared to calibrated accelerometer cut-off points in the quantification of sedentary behaviour and physical activity in older adults. Tully MA, editor. PLoS One. 2018 Apr 19;13(4):e0195712.

59. Prince S, Adamo K, Hamel M, Hardt J, Gorber S, Tremblay M. A comparison of direct versus self-report measures for assessing physical activity in adults: a systematic review. Int J Behav Nutr Phys Act. 2008;1(5):56-80.

60. Katz J. Total joint replacement in osteoarthritis. Best Pract Res Clin Rheumatol [Internet]. 2006 Feb;20(1):145-53.

61. Ryan RM, Deci EL. Self-determination theory and the facilitation of intrinsic motivation, social development, and well-being. Am Psychol. 2000 Jan;55(1):68-78.

62. Collard RM, Boter H, Schoevers RA, Oude Voshaar RC. Prevalence of Frailty in Community-Dwelling Older Persons: A Systematic Review. J Am Geriatr Soc. 2012 Aug;60(8):1487-92.

63. Sternberg SA, Schwartz AW, Karunananthan S, Bergman H, Mark Clarfield A. The Identification of Frailty: A Systematic Literature Review. J Am Geriatr Soc. 2011 Nov 1;59(11):2129-38.

64. Guralnik JM, Simonsick EM, Ferrucci L, Glynn RJ, Berkman LF, Blazer DG, et al. A short physical performance battery assessing lower extremity function: association with self-reported disability and prediction of mortality and nursing home admission. J Gerontol. 1994;49(2):M85-94.

65. Katz S, Downs TD, Cash HR, Grotz RC. Progress in development of the index of ADL. Gerontologist. 1970;10(1):20-30.

66. Sheikh VI, Yesavage VA. Geriatric Depression Scale (GDS): recent evidence and development of a shorter version. In: Brink TL, editor. Clinical 
gerontology: a guide to assessment and intervention. New York (US): Haworth Press; 1986.

67. Zigmond AS, Snaith RP. The hospital anxiety and depression scale. Acta Psychiatr Scand. 1983;67(6):361-70.

68. Molloy DW, Standish TI. A guide to the standardized Mini-Mental State Examination. Int psychogeriatrics. 1997;9(Suppl 1):87-94; discussion 143-50.

69. Cohen S, Mermelstein R, Kamarck T, Hoberman HM. Measuring the Functional Components of Social Support. In: Social Support: Theory, Research and Applications. Dordrecht (The Netherlands): Springer; 1985. p. 73-94.

70. Franceschi C. Inflammaging as a major characteristic of old people: can it be prevented or cured? Nutr Rev. 2007;65(12 Pt 2):S173-6.

71. Kiecolt-Glaser JK, Preacher KJ, MacCallum RC, Atkinson C, Malarkey WB, Glaser R. Chronic stress and age-related increases in the proinflammatory cytokine IL-6. Proc Natl Acad Sci U S A. 2003;100(15):9090-5.

72. Walston J, Hadley EC, Ferrucci L, Guralnik JM, Newman AB, Studenski SA, et al. Research agenda for frailty in older adults: toward a better understanding of physiology and etiology: summary from the American Geriatrics Society/National Institute on Aging Research Conference on Frailty in Older Adults. J Am Geriatr Soc. 2006;54(6):991-1001.

73. Rantanen T, Guralnik JM, Foley D, Masaki K, Leveille S, Curb JD, et al. Midlife hand grip strength as a predictor of old age disability. JAMA. 1999;281(6): 558-60.

74. Musumeci G, Castrogiovanni P, Coleman R, Szychlinska MA, Salvatorelli L, Parenti R, et al. Somitogenesis: From somite to skeletal muscle. Acta Histochem. 2015;117(4-5):313-28.

75. Sipila S, Heikkinen E, Cheng S, Suominen H, Saari P, Kovanen V, et al. Endogenous hormones, muscle strength, and risk of fall-related fractures in older women. J Gerontol A Biol Sci Med Sci. 2006;61(1):92-6.

76. Phillips SK, Rook KM, Siddle NC, Bruce SA, Woledge RC. Muscle weakness in women occurs at an earlier age than in men, but strength is preserved by hormone replacement therapy. Clin Sci. 1993;84(1):95-8.

77. Weiss EP, Spina RJ, Holloszy JO, Ehsani AA. Gender differences in the decline in aerobic capacity and its physiological determinants during the later decades of life. J Appl Physiol. 2006;101(3):938-44.

78. Sipilä S, Narici M, Kjaer M, Pöllänen E, Atkinson RA, Hansen M, et al. Sex hormones and skeletal muscle weakness. Biogerontology. 2013;14(3):231-45.

79. Lachman ME. Development in Midlife. Annu Rev Psychol. 2004;55(1):305-31.

80. Kovanen V, Aukee P, Kokko K, Finni T, Tarkka IM, Tammelin T, et al. Design and protocol of Estrogenic Regulation of Muscle Apoptosis (ERMA) study with 47 to 55-year-old women's cohort. Menopause. 2018;25(9):1020-32. doi: 10.1097/GME.0000000000001117

81. Cruz-Jentoft AJ, Bahat G, Bauer J, Boirie Y, Bruyère O, Cederholm T, et al. Sarcopenia: revised European consensus on definition and diagnosis. Age Ageing. 2019;48(1):16-31.

82. Musumeci G, Musumeci, Giuseppe. Sarcopenia and Exercise "The State of the 
Art.” J Funct Morphol Kinesiol. 2017;2(4):40.

83. Schrack JA, Knuth ND, Simonsick EM, Ferrucci L. "IDEAL” aging is associated with lower resting metabolic rate: the Baltimore Longitudinal Study of Aging. J Am Geriatr Soc. 2014;62(4):667-72.

84. Kim S, Welsh DA, Ravussin E, Welsch MA, Cherry KE, Myers L, et al. An elevation of resting metabolic rate with declining health in nonagenarians may be associated with decreased muscle mass and function in women and men, respectively. J Gerontol A Biol Sci Med Sci. 2014;69(6):650-6.

85. Nielsen J. Systems Biology of Metabolism: A Driver for Developing Personalized and Precision Medicine. Cell Metab. 2017;25(3):572-9.

86. Pierik VD, Meskers CGM, Van Ancum JM, Numans ST, Verlaan S, Scheerman $\mathrm{K}$, et al. High risk of malnutrition is associated with low muscle mass in older hospitalized patients-a prospective cohort study. BMC Geriatr. 2017;17(1):118.

87. Zamboni M, Mazzali G, Fantin F, Rossi A, Di Francesco V. Sarcopenic obesity: a new category of obesity in the elderly. Nutr Metab Cardiovasc Dis. 2008;18(5):388-95.

88. Scarmeas N, Anastasiou CA, Yannakoulia M. Nutrition and prevention of cognitive impairment. Lancet Neurol. 2018;17(11):1006-15.

89. Reddan JM, Macpherson H, White DJ, Scholey A, Pipingas A. Examining the relationship between nutrition and cerebral structural integrity in older adults without dementia. Nutr Res Rev. 2019;32(1):79-98.

90. Presley TD, Morgan AR, Bechtold E, Clodfelter W, Dove RW, Jennings JM, et al. Acute effect of a high nitrate diet on brain perfusion in older adults. Nitric Oxide. 2011;24(1):34-42.

91. Cunnane SC, Plourde M, Pifferi F, Bégin M, Féart C, Barberger-Gateau P. Fish, docosahexaenoic acid and Alzheimer's disease. Prog Lipid Res. 2009;48(5):239-56.

92. Santos NC, Costa PS, Cunha P, Portugal-Nunes C, Amorim L, Cotter J, et al. Clinical, physical and lifestyle variables and relationship with cognition and mood in aging: a cross-sectional analysis of distinct educational groups. Front Aging Neurosci. 2014;6:21.

93. Strauss E, Sherman EM., Spreen O. A compendium of neuropsychological tests: administration, norms and commentary. New York (US): Oxford University Press; 2006.

94. Lezak M, Howieson D, Loring D. Neuropsychological assessment. New York (US): Oxford University Press; 2004.

95. Wechsler D. Wechsler adult intelligence scale (WAIS-III). San Antonio (US): Harcourt Assessment; 1997.

96. Buschke H, Sliwinski M, Kuslansky G, Lipton RB. Aging, encoding specificity, and memory change in the Double Memory Test. J Int Neuropsychol Soc. 1995;1(5):483-93.

97. Folstein MF, Folstein SE, McHugh PR. "Mini-mental state”. A practical method for grading the cognitive state of patients for the clinician. J Psychiatr Res. 1975;12(3):189-98.

98. Schröder H, Fitó M, Estruch R, Martínez-González MA, Corella D, Salas- 
Salvadó J, et al. A Short Screener Is Valid for Assessing Mediterranean Diet Adherence among Older Spanish Men and Women. J Nutr. 2011;141(6): 1140-5.

99. Lowe CJ, Reichelt AC, Hall PA. The Prefrontal Cortex and Obesity: A Health Neuroscience Perspective. Trends Cogn Sci. 2019;23(4):349-61.

100. Lawton MP, Brody EM. Assessment of older people: self-maintaining and instrumental activities of daily living. Gerontologist. 1969;9(3):179-86.

101. Nagelkerk J, Reick K, Meengs L. Perceived barriers and effective strategies to diabetes self-management. J Adv Nurs. 2006;54(2):151-8.

102. Zorbas C, Palermo C, Chung A, Iguacel I, Peeters A, Bennett R, et al. Factors perceived to influence healthy eating: a systematic review and metaethnographic synthesis of the literature. Nutr Rev. 2018;76(12):861-74.

103. Albarran NB, Ballesteros MN, Morales GG, Ortega MI. Dietary behavior and type 2 diabetes care. Patient Educ Couns. 2006;61(2):191-9.

104. Steptoe A, Perkins-Porras L, McKay C, Rink E, Hilton S, Cappuccio FP. Behavioural counselling to increase consumption of fruit and vegetables in low income adults: randomised trial. BMJ. 2003;326(7394):855.

105. Schoeller DA. Limitations in the assessment of dietary energy intake by selfreport. Metabolism. 1995;44(2 Suppl 2):18-22.

106. Wenger GC. A network typology: From theory to practice. J Aging Stud. 1991;5(2):147-62.

107. Kaiser MJ, Bauer JM, Ramsch C, Uter W, Guigoz Y, Cederholm T, et al. Validation of the Mini Nutritional Assessment short-form (MNA-SF): a practical tool for identification of nutritional status. J Nutr Health Aging. 2009;13(9):782-8.

108. Garagnani P, Bacalini MG, Pirazzini C, Gori D, Giuliani C, Mari D, et al. Methylation of ELOVL2 gene as a new epigenetic marker of age. Aging Cell. 2012;11(6):1132-4.

109. Horvath S. DNA methylation age of human tissues and cell types. Genome Biol. 2013;14(10):R115.

110. Hannum G, Guinney J, Zhao L, Zhang L, Hughes G, Sadda S, et al. Genomewide Methylation Profiles Reveal Quantitative Views of Human Aging Rates. Mol Cell. 2013;49(2):359-67.

111. Horvath S, Raj K. DNA methylation-based biomarkers and the epigenetic clock theory of ageing. Nat Rev Genet. 2018;19(6):371-84.

112. Jylhävä J, Pedersen NL, Hägg S. Biological Age Predictors. EBioMedicine. 2017;21:29-36.

113. Santoro A, Pini E, Scurti M, Palmas G, Berendsen A, Brzozowska A, et al. Combating "inflammaging" through a Mediterranean whole diet approach: the NU-AGE project rationale. Free Radic Biol Med. 2013;65:S3-4. 
114. Spencer CCA, Su Z, Donnelly P, Marchini J. Designing genome-wide association studies: Sample size, power, imputation, and the choice of genotyping chip. PLoS Genet. 2009;5(5):e1000477. doi: 10.1371/journal.pgen.1000477

How to cite this article:

Whittaker AC, Asamane EA, Aunger JA, Bondarev D, Cabbia A, Doody PD, et al. Physical Activity and Nutrition INfluences in Ageing: Current Findings from the PANINI Project. Adv Geriatr Med Res. 2019;1:e190005. https://doi.org/10.20900/agmr20190005 